NASA Contractor Report 191027

AIAA-93-0215

\title{
A Numerical Study of Mixing in Supersonic Combustors With Hypermixing Injectors
}

J. Lee

Sverdrup Technology, Inc.

Lewis Research Center Group

Brook Park, Ohio

December 1992 


\title{
A Numerical Study of Mixing in Supersonic Combustors with Hypermixing Injectors
}

\author{
J. Lee* \\ Sverdrup Technology, Inc. \\ NASA Lewis Research Center Group \\ 2001 Aerospace Parkway \\ Brook Park, $\mathrm{OH} 44142$
}

\begin{abstract}
A numerical study was conducted to evaluate the performance of wall mounted fuel-injectors designed for potential Supersonic Combustion Ramjet(SCRAM-jet) engine applications. The focus of this investigation was to numerically simulate existing combustor designs for the purpose of validating the numerical technique and the physical models developed. Three different injector designs of varying complexity were studied to fully understand the computational implications involved in accurate predictions. A dual transverse injection system and two streamwise injector designs were studied. The streamwise injectors were designed with swept ramps to enhance fuelair mixing and combustion characteristics at supersonic speeds without the large flow blockage and drag contribution of the transverse injection system. For this study, the Mass-Averaged Navier-Stokes equations and the chemical speties continuity equations were solved. The computations were performed using a finite-volume implicit numerical technique and multiple block structured grid
\end{abstract}

* Principal Research Scientist, Member AIAA.

Copyright(C) 1992 by American Institute of Aeronautics and Astronautics, Inc. No copyright is asserted in United States under Title 17, U. S. Code. The U. S. Government has a royalty free license to exercise all rights under the copyright claimed herein for Governmental purpose. All other rights are reserved by the copyright owner. system. The interfaces of the multiple block structured grid systems were numerically resolved using the fluxconservative technique. Detailed comparisons between the computations and existing experimental data are presented. These comparisons show that numerical predictions are in agreement with the experimental data. These comparisons also show that a number of turbulence model improvements are needed for accurate combustor flowfield predictions.

\section{Introduction}

In order to design a more efficient and reliable supersonic propulsion system for high speed vehicles, such as the National Aero-Space Plane(NASP), it is essential to be able to accurately predict the chemically reacting flow field inside the combustor. In particular, a number of physical mechanisms affecting the mixing and combustion must be modeled correctly in order that the combustors can be readily analyzed and optimized. The eventual goal of this study is to numerically simulate three dimensional turbulent non-reacting flow fields in a supersonic combustor to investigate possible fuel-air mixing mechanisms which can eventually be used to increase the overall efficiency of present and future engine designs. In this study, we will deal primarily with the analysis of non-reacting flow situations inside combustors to assess the effectiveness of a popular zero equation turbulence model in complex three dimensional combustor flowfield predictions. Comparisons between the computational predictions made 
in this study and the available experimental data show that even a simple turbulence model will generate reasonable predictions of very complex flowfields inside the combustors. However, this study also shows that further improvements of the numerical technique and physical models are needed so that more accurate and economical predictions can be made for a wide range of designs and design conditions. This present study is part of a complete development and validation ${ }^{1}$ effort designed to produce a practical numerical technique for future design analysis of supersonic/hypersonic propulsion devices.

In supersonic flow, low combustor efficiency is a consequence of the low shear-mixing caused by compressibility effects, and the extremely short combustor residence time of the injected fuel. ${ }^{2}$ In an earlier study of the supersonic shear-layer, Brown and Roshko ${ }^{3}$ showed that the spreading rate of a supersonic mixing layer decreased dramatically with increasing freestream Mach number. The compressible spreading rates observed were about a factor of three less than the incompressible mixing-layer spreading rate generated by the same density ratio. A similar conclusion was reached by Papamoschou and Roshko ${ }^{4}$ based on a theoretical analysis of shear-layers. Furthermore, they showed that the reduction in spreading rate correlated most closely with the convective Mach number. The convective Mach number is defined as the differential velocity normalized by the speed of sound. An independent linear stability theory analysis of Ragab and $\mathrm{Wu}^{5}$ reached the same conclusion. These investigations, both theoretical and experimental, have shown that difficulty exists in achieving a high degree of mixing in high Mach number flows.

Therefore, a firm understanding of the physical mechanisms which can be used to enhance the mixing process is necessary to minimize the compressibility losses and to design a configuration of the fuel injector that is optimal in terms of mixing and combustion efficiencies. Guirguis et al. ${ }^{6,7}$ observed, in a two-dimensional mixing- layer simulation, that a larger pressure differential between two supersonic streams enhanced the mixing process and increased the spreading rate of the mixing-layer. Therefore, a number of investigators have introduced this effect into their streamwise injector designs through additional compression/expansion surfaces. Some investigators believe that the initial shear and the vorticity generated by spanwise convolutions $s^{8,9}$ and externally generated swirl will produce optimal combustor designs. Therefore, these concepts have been incorporated into the swept-piano key injectors ${ }^{9}$ and swirling nozzle designs. ${ }^{10,11,12}$ Drummond et. al. ${ }^{13}$ and Marble et. al. ${ }^{14}$ proposed that externally generated vorticity be used to generate additional mixing; Drummond $^{13}$ numerically showed that the swept wedge injector, which generates a strong streamwise vorticity, has mixing characteristics far superior than its un-swept counterpart. In the work of Marble et. al. ${ }^{14}$ planar shock-waves were used to enhance the mixing between co-flowing circular jets of fuel and air. Marble showed that a jet processed by an oblique shock-wave will produce a strong vortical component due to the interaction between the density differential of fuel-air and the strong pressure gradient across the shock-wave. Some of the behavior changes caused by this interaction can be illustrated through the use of the vorticity transport equation ${ }^{14}$ and were later numerically illustrated by Drummond. ${ }^{13}$ There are numerous other suggestions for using the unsteady mechanisms related to the dynamics of the shock-wave/boundary-layer, shock-wave/vortex, and shock-wave/ shock-wave interactions to generate additional fluctuating energies required for mixing. Kumar et. al. ${ }^{2}$ further studied some of these mixing enhancement techniques. A number of these concepts have been incorporated into the latest combustor/fuel injector designs. In the present study, the computations of combustor/fuel injector designs were conducted to assess injector effectiveness of these concepts as well as the validity of the numerical and physical models.

This analysis of the mixing combustor flowfield was conducted using the Reactive Propulsion code based on a Lower/Upper(LU) decomposition Scheme(RPLUS). The nine species-eighteen step finiterate chemistry model in the RPLUS code has already been tested in similar laminar combustor flows. ${ }^{1,15}$ Therefore, the primary focus of this investigation was the testing of the numerics and the turbulence model using hypersonic and supersonic non-reacting hypermixing problems. This study showed that the complex three dimensional flow structures inside combustors can be accurately predicted using the RPLUS code. However, several turbulence model improvements were necessary to realistically simulate the turbulent mass diffusion. Furthermore, even with these corrections the extent and strength of spreading due to mixing were poorly predicted in some regions of the flow.

The two primary high speed combustors designs investigated use the streamwise injection system and the staged transverse injection system. The streamwise injection system is desirable because of its potential to have low total pressure losses. This contributes less to the overall internal drag of the engine and reduces the risk of the engine "un-starting." However, this technique is capable of only low fuel penetration and therefore is low in overall mixing efficiency. The transverse injection system is attractive because of the high fuel penetration characteristics and higher mixing efficiency. However, this design can cause large pressure losses and therefore has higher internal drag contribution. Most researchers agree that some optimized combination of these two techniques will produce the best high speed 
combustor design. Therefore, both streamwise and transverse injections were studied to demonstrate the capabilities the numerical and the physical models developed.

\section{Governing Equations}

The three dimensional Navier-Stokes, energy, and species continuity equations governing the chemical reactions are numerically solved on multiple-block structured grid systems. These governing equations can be written in a conservative form given by the following,

$$
\frac{\partial}{\partial t} Q+\frac{\partial}{\partial x}\left(E-E_{v}\right)+\frac{\partial}{\partial y}\left(F-F_{v}\right)+\frac{\partial}{\partial z}\left(G-G_{v}\right)=H
$$

The vectors $E, F$, and $G$ are flux vectors and $H$ is the source vector containing the chemical source terms. They are defined to be the following

$$
\begin{gathered}
Q=\left(\begin{array}{c}
\rho \\
\rho u \\
\rho v \\
\rho w \\
\rho E_{t} \\
\rho Y_{i}
\end{array}\right) \quad H=\left(\begin{array}{c}
0.0 \\
0.0 \\
0.0 \\
0.0 \\
0.0 \\
\omega_{i}
\end{array}\right) \\
E=\left(\begin{array}{c}
\rho u \\
\rho u^{2}+p \\
\rho u v \\
\rho u w \\
u(\rho e+p) \\
\rho u Y_{i}
\end{array}\right) E_{v}=\left(\begin{array}{c}
0.0 \\
\tau_{x x} \\
\tau_{x y} \\
\tau_{x z} \\
u \tau_{x x}+v \tau_{x y}+w \tau_{x z}-q_{x} \\
-\rho u_{i} Y_{i}
\end{array}\right) \\
F=\left(\begin{array}{c} 
\\
\rho v \\
\rho u v \\
\rho v^{2}+p \\
\rho u w \\
v(\rho e+p) \\
\rho v Y_{i}
\end{array}\right) F_{v}=\left(\begin{array}{c}
\tau_{y x} \\
\tau_{y y} \\
\tau_{y z} \\
u \tau_{y x}+v \tau_{y y}+w \tau_{z y}-q_{y} \\
-\rho v_{i} Y_{i}
\end{array}\right)
\end{gathered}
$$

$$
G=\left(\begin{array}{c}
\rho w \\
\rho u w \\
\rho v w \\
\rho w^{2}+p \\
w(\rho e+p) \\
\rho w Y_{i}
\end{array}\right) \quad G_{v}=\left(\begin{array}{c}
0.0 \\
\tau_{z x} \\
\tau_{z y} \\
\tau_{z z} \\
u \tau_{z x}+v \tau_{z y}+w \tau_{y z}-q_{z} \\
-\rho w_{i} Y_{i}
\end{array}\right) \text { (5) }
$$

where $\rho$ is the mixture density, $u, v$, and $w$ are the mean velocities, $e$ is the total energy and $Y_{i}$ is the species mass fraction. $\omega_{i}$ are the source terms for the species equations. $\tau_{l k}$ and $q_{l}$ are the viscous stresses and heat fluxes. $u_{\mathrm{i}}, v_{\mathrm{i}}$, and $w_{\mathrm{i}}$ are mass diffusion velocitics; i denotes the number of species.

The laminar portion of the conductivity, viscosity, and diffusivity are computed from fourth-order polynomial approximations. The coefficients required for these thermodynamic approximations are taken from Gordon and McBride. ${ }^{16}$ Once the species viscosity has been found, the mixture viscosity is computed from Wilke's law. ${ }^{17}$ The binary mass diffusivity between the species is obtained by using the Chapman-Enskog theory in conjunction with the Lennard-Jones inter-molecular potential energy functions. ${ }^{17}$ For the two species(air to air) mixing computations, the parameters needed to compute the inter-species diffusion, the effective collision diameter and the effective temperature have been taken to be $3.617^{\circ} \mathrm{A}$ and $97^{\circ} \mathrm{K}$ for air. The chemical source term $\left(\omega_{i}\right)$ contribution is assumed to be zero. The mass diffusion velocities are evaluated using Fick's law. For the non-reacting mixing computations, one additional species continuity equation for the secondary air is solved to closely match the mass and diffusive property of the experiments which used (iodine or ethylene) seeded air as the injectant. In these mixing computations the first species represents the freestream air and the second species represents the injected air. A zero-equation algebraic turbulence model proposed by Baldwin and Lomax ${ }^{18}$ was used in the computations presented. This turbulence model was modified with Buleevinverse square length scale formulation ${ }^{19}$ to simulate the interaction effects of multiple no-slip walls in corner situations. The turbulence model maintains consistent lowReynolds number damping characteristics between the grid blocks, and therefore a continuous eddy viscosity profile exists between the grid blocks. The effects of temperature and species fluctuations are neglected in this turbulence model. Initially, the turbulent Prandtl number and Schmidt numbers are assumed to be 0.9 and 1.0, respectively. However, the turbulent Schmidt num- 
ber value was later reduced to 0.50 in order to increase the turbulent diffusion necessary in these simulations.

\section{Numerical Technique}

Once the thermodynamic, chemical, diffusion and turbulent properties have been computed, the governing equations are implicitly formulated and numerically solved. The conservation equations of mass, momentum, energy, and species are solved in a fully coupled implicit manner using central differencing. Steady-state numerical solutions are achieved by iterating the solution using the Symmetric Successive Over Relaxation (SSOR) numerical technique. ${ }^{15}$ The SSOR technique diagonalizes the flow equations and then solves them using a series of scalar inversions. The chemical source terms in species continuity equations are implicitly treated and are solved using LU decomposition. In order to reduce the core memory size, each of grid blocks is numerically operated on and then written out to the Solid State Disk(SSD) at each iteration. The interconnecting faces between the blocks did not have faces which matched cell to cell. As a result, the information travel between these non-matching grid system was handled according to the flux-conservative technique developed by Moon. ${ }^{20}$ The use of independently generated blocks of grid to model each region of the flow field avoided many difficulties that would have resulted had a single block has been used.

\section{Discussion}

In this study non-reacting injector/combustor flowfields were studied to validate the numerical technique and the zero-equation turbulence model developed for the RPLUS code. Presently, only the non-reacting experiments were studied to reduce the computational complexity and still retain all of the parameters previously shown to be difficult to predict, such as separation and spreading rate of the mixing-layer. Further studies of reacting flow-fields are necessary to validate the complete turbulence to chemical interaction model since the exothermic chemical reactions have been shown to enhance the mixing characteristics(Givi et. al. ${ }^{21}$ ). However, much of the numerics and the turbulence model behavior can be studied using the readily available nonreacting mixing-layer data. This database includes the measurements of fuel(injected gas) mass fractions, mean velocity, static pressure and temperature profiles. The hyper-mixing injector/combustor models used in the experiments conducted at NASA Lewis Research Center, ${ }^{22}$ Langley Research Center, ${ }^{23}$ and University of Virginia $^{24,25}$ have been studied.

\subsection{Dual Transverse Injection Model of McDaniel et. al.}

One experimental study of a transverse injection system was conducted by McDaniel et. al. ${ }^{24}$ The geometry of McDaniel's constant area combustor model with two transverse injectors is shown in Figure 1. In this design, a rearward facing step is used to create a recirculation region that acts as a flame-holder. This rearward facing step is followed by dual fuel-injection ports located at the bottom wall of the test section. A typical flow structure over the back-step is illustrated in Figure 2. The width of the model is $30.48 \mathrm{~mm}$ and the height of the model is $21.29 \mathrm{~mm}$. The step height is $3.1845 \mathrm{~mm}(\mathrm{H})$ and the injector diameter(D) is $1.93 \mathrm{~mm}$. The injectors are located at $9.55 \mathrm{~mm}$ and $22.29 \mathrm{~mm}$ from the back-step, respectively.

The stagnation conditions of pressure and temperature used to generate the freestream flowfield are $274 \mathrm{KPa}$ and $300^{\circ} \mathrm{K}$. The incoming stream of air is assumed to be fully-developed at a location $6 \mathrm{~mm}$ (3D) upstream of the back-step in the computation. The incoming boundary-layer profile was modeled using the Iog-law and adiabatic wall assumptions. ${ }^{26}$ Two species air-to-air mixing computations were performed in this study to match the iodine-seeded air used in the experimental investigation of McDaniel. The mole fraction of the injected secondary air, extensively measured using Planar Laser Induced Iodine Fluorescence(PLIIF), was compared with the computed solution.

In order to reduce computational resource requirements, the combustor flowfield was assumed to be symmetric about a XY-plane located at the centerline of the injectors. Figure 3 illustrates a typical two-block grid system used in the computations. The first grid block, 19 by 30 by 45 in size, was used to model the flow upstream of the back-step. The second grid, 77 by 45 by 45 , was used to model only the test section of this combustor. This 181,575 cell computation required 17 Cray Mega Words(CMW) of memory. The grid cells normal to the three side walls and the cells near injectors have been stretched using a hyperbolic tangent based stretching function to achieve a grid size $\left(\mathrm{y}^{+}\right)$of approximately 1.0. The circular injectors were modeled with rectangular grid cells. Typically, there are 20 to 25 rectangular cells modeling the injector exit plane. All of the combustor walls were assumed to be no-slip and adiabatic, except the rear-side of the back-step where a slip wall boundary condition was maintained. Typical convergence characteristics of a numerical solution obtained are illustrated through the global residual curves shown in Figure 4. For a converged solution, the numerical iterations were performed to achieve approximately three orders of magnitude reduction of the density(L1) and mass flux(L2) residuals. This convergence usually 
required 2500 iterations and approximately 6.5 Cray YMP CPU hours.

Injector characterization is difficult and too computationally intensive to be included as a part of the combustor flowfield solution. Therefore, a best estimate of the injector exit static conditions has been used. However, the fixed boundary condition assumption ignores the effect of the injector on the boundary-layer interactions, even though this effect can be significant. Furthermore, some uncertainties in the measurements do exist because of the sensitivity of the measurements to various experimental uncertainties. ${ }^{24}$ Therefore, some considerations were given to the injector characterization.

The injector exit boundary condition reported by McDaniel et. al. corresponds to conditions generated by a perfectly choked flow. The mass flow rate computed from this static condition will introduce higher mass flow rates $(1.78 \mathrm{~g} / \mathrm{s})$ than measured $(1.60 \mathrm{~g} / \mathrm{s})$. This deficiency can be removed by either adjusting the injector exit static conditions or by adjusting the size of the injector nozzle. Small variations in injector exit conditions has negligible effect on the main combustor flow field predictions if the mass flow rate of $1.60 \mathrm{~g} / \mathrm{s}$ is maintained. A higher mass flow rate will choked the flow inside of the combustor leading to much higher static conditions.

For the computation presented, we have assumed that the injectors were choked slightly upstream of the exit plane and a small amount of expansion has occurred at the first cell where the boundary conditions were implemented. Therefore, a supersonic Mach number of 1.25 has been used as the boundary condition. This injector exit Mach number is approximately the average of measured exit Mach number values reported by $\mathrm{McDaniel}$ et. al. ${ }^{24}$ The effect of non-uniformity in the injector flowfield has not been considered in this study. The injector pressure and temperature, required for the computations have been obtained from a one dimensional analysis that maintains the measured mass flow rate of $1.60 \mathrm{~g} / \mathrm{s}$. The physical size of the injectors were maintained as measured and the static pressure of the injected gas was adjusted to match the measured mass flow rates. Therefore, the computed static pressure and temperature of the injector are $97 \mathrm{KPa}$ and $228^{\circ} \mathrm{K}$, respectively.

Figure 5 shows the computed total mass flow rates and freestream air flow rates along the tunnel. Note that the computed total and injected mass flow rate of each injector reflects only half the reported values because only half of the combustor was numerically resolved. The computed mass flow rate $(0.0958 \mathrm{Kg} / \mathrm{s})$ of the freestream flow is approximately 4 percent lower than the reported value $(0.10 \mathrm{Kg} / \mathrm{s})$. The consequences of slight lower mass flow rate in the test section flow were not studied. The injected mass flow adds an additional
$0.80 \mathrm{~g} / \mathrm{s}$ of flow at the first injector, raising the total mass flow rate to $0.0966 \mathrm{Kg} / \mathrm{s}$ at the first injector, and an additional $0.80 \mathrm{~g} / \mathrm{s}$ of flow at the second injector, leading to the final value of $0.0974 \mathrm{Kg} / \mathrm{s}$. The overall numerical error in the prediction of the mass flow rate is less than 4 percent for the injected gas and total mass flow rates.

Comparisons of computed and measured velocity, pressure and temperature profiles are shown in Figures 6 through 9. Several comparisons made along the centerplane $(\mathrm{Z} / \mathrm{D}=0.0)$ and at a plane a half diameter away from the centerplane $(\mathrm{Z} / \mathrm{D}=0.5)$ locations are presented. In addition, the computation resolving all three walls of the test section is compared to other computations in which the visous displacement effects are neglected(denoted as $1 \mathrm{~W}$-all and $2 \mathrm{~W}$-all) at various sides of the combustor walls. Figure 6 shows the velocity, pressure and temperature profile comparisons at the center of the first injector $(\mathrm{X} / \mathrm{D}=0.0)$. $\mathrm{U}$-velocity prediction is in agreement with the PLIIF measurements except in the high shear region near the injector exit( $\mathrm{Y} / \mathrm{D}<3.0)$. Here, the predictions are lower than the measured values because of the limitations imposed by the one dimensional injector model. Figure 6a shows the V-velocity profile comparison. The computed near wall V-velocity does not match the experimental data exactly because of the injector boundary condition. The computed temperature and pressure are in reasonable agreement with the experimental data, except at the peak of the penetration, where the strength of the compression/expansion is over predicted. Figure 7 show similar comparisons for a flow region three diameters downstream of the first injector. The static pressure and temperature profile across the test section are well predicted. However, the near wall temperature is over predicted by 40 percent. This discrepancy is caused in part by the zero equation turbulence model's inability to predict separation/reattachment characteristics. Although the uncertainties in the measurements, especially near the wall, is also a major factor in this discrepancy, it is clear that a more accurate turbulence model is needed to study this difficulty. Figure 8 shows similar comparisons of velocity, pressure and temperature profiles at the center of the second injector $(X / D=6.6)$. Once again, the peak values of the expansion/compression characteristics are over predicted. However, both the velocity components and inviscid core of the pressure and temperature profiles are in agreement with experimental data. Figure 9 shows a typical comparison of velocities, pressure and temperature profiles at a station one half diameter away from the centerline and three diameters downstream of the first injector. Figure 9 clearly shows that the velocities and the pressure profiles are well predicted. These figures also show that the wall temperature in the separated region between the two injector is still over predicted by 33 percent. These profiles also show that while some of the under-expanded jet characteristics have been cap- 
tured by the computations, much of the near injector/ boundary-layer interaction has not been captured by the computation.

Figures 10 and 11 show the computed centerline pressure and temperature. These contours are in quantitative and qualitative agreement with the planar measurements reported by McDaniel et. al. ${ }^{24}$ These figures clearly show the underlining physical behavior of this flowfield; including the expansion of the supersonic flow over the back-step, characteristics of the two under-expanded jets, and the bow shock formed around the columns of the injected gas. The pressure contour, shown by Figure 10, clearly shows that the expansion caused by the back-step is limited by the injected gas stream from the first injector and that the ideal expansion ratio $\left(\mathrm{P}_{2} / \mathrm{P}_{1}\right)$ of 0.38 is not reached. This is in agreement with the experimental observation of McDaniel. ${ }^{24}$ The measured pressure value of the ratio for this expansion is 0.53 and the computed result is 0.57 . Figure 11 shows that the wall temperature at the backface of the step is colder than expected since the viscous wall boundary condition was not maintained in the numerical model.

Figure 12 shows the centerline $(\mathrm{Z} / \mathrm{D}=0.0)$ mass fraction contour comparison between the experimental data obtained by McDaniel et. al. ${ }^{24}$ and the prediction. This figure shows that most of the important flowfield features of the injected gas, including the upstream penetration of the injected gas, are well captured by the computation. The mass fraction levels are indicated by the color bar. This figure shows that the computed results are in quantitative agreement with the measured contour. The penetration height of the second injector is almost twice that of the first stream of gas. This deeper penetration is facilitated by the first column of injected gas acting as a buffer and creating much more favorable static conditions for the second injector.

Several cross section of the mass fraction predictions are compared with experimentally measured contours in Figures 13a through 13d. Figure 13a shows the mass fraction contour comparison at three diameters upstream of the first injector. This comparison shows that the size of the recirculation behind the back-step, and the extent to which that region has been able to capture the injected gas are, well predicted; up to 20 percent of the injected gas can be captured in the recirculation region behind the back-step. Figure $13 \mathrm{~b}$ and $13 \mathrm{~d}$ show mass fraction comparisons at $\mathrm{X} / \mathrm{D}=0.0$ and $\mathrm{X} / \mathrm{D}=6.6$. These comparisons are at the center of the first injector and the second injector. The experimental data shows "mushrooming" characteristic of the under-expanded jet shape. However, the exact shape of the injected plume has not been captured by the prediction. This discrepancy may have occurred because the injectors to boundary-layer interactions were not modeled as a part of the flow solution. The data shows the injector exit plane to be three dimensional. However, the injectors are modeled as a one dimensional surfaces with fixed boundary conditions in the computations. Therefore, much of the near injector interactions are not numerical modeled. It should also be noted that predicted regions around the plume perimeter is much thinner than the experimental measurements. It is readily evident from these thinner regions that the total diffusion of injected gas predicted is too small and is restricted to a narrower region of the flow than experimentally observed. This difficulty is consistent with an earlier observation of Eklund et. al., ${ }^{27}$ who also showed that the Baldwin-Lomax turbulence model tends to underpredict the spreading behavior of simple shear-layers. Much of this deficiency can be attributed to use of the empirically calibrated wake function for attached flows to determine the length scales of the non-attached flow situations. However, other characteristics, such as the penetration depth of the injected gas and the extent of cross stream spreading of the injected mass captured by the boundary-layer are reasonably well predicted. Figure $13 \mathrm{c}$ shows the mass fraction contour comparison at a location three diameter form the first injector $(X / D=3.1)$. This station shows the typical roll up behavior caused by the curved shockwave form around the first column of the injected gas has been reasonably captured by the prediction. The circulation created by the curved bow shock causes the injected core of gas to take on a butterfly like shape.

Further quantitative assessment of the mixing and spreading characteristics can be made using mixing effi$\operatorname{ciency}(\eta)$. Mixing efficiency of both reacting and nonreacting flows is defined as the fraction of the least available reactant that can react if the flow was brought to chemical equilibrium. McDaniel suggested that for the air to air mixing the efficiency expression reduces to the area ratio where 4 to 75 percent injected mass fraction ratio exists. The range of the mass fraction used corresponds to the static flammability limit of hydrogenair combustion. Figure 14 shows the comparison of the mixing efficiency of the prediction and the measurements. This figure shows that the prediction clearly does not do well in predicting the spreading rate of the mass injected. Although the upstream penetration due to the recirculation has been captured.

\subsection{Streamwise Mach 2.0 Swept Injector of Hartfield et. al.}

An experimental study of a streamwise injection system was conducted by Harfield et. al. ${ }^{25}$ Although the geometry of the streamwise swept injector is very difficult to resolve using a conventional grid system, it was handled easily using a multiple-block grid system. A typical geometry of the swept-injector model is illustrated in Figure 15 and a schematic of the flow field is shown in Figure 16. The ramp angle $\left(A_{r}\right)$ and swept angle $\left(A_{s}\right)$ are 9.5 degrees for this injector model. The 
height $(\mathrm{H})$ of the swept injector is $4.9 \mathrm{~mm}$. The injector nozzle is located at the backface of the ramp and is designed to generate a supersonic injection. Typical static pressure and temperature are $33.5 \mathrm{KPa}$ and $167^{\circ} \mathrm{K}$, respectively. The height and the width of the combustor model are $18.1 \mathrm{~mm}$ and $30.1 \mathrm{~mm}$, respectively.

The freestream Mach number of the Hartfield et. $\mathrm{al}^{25}$ experiment was approximately 2.0 . The stagnation pressure and temperature were $262 \mathrm{KPa}$ and $300^{\circ} \mathrm{K}$, respectively. This Mach 2 flow was generated using a two dimensional rectangular nozzle. This nozzle also generates complex three dimensional flow features at the corners of the test section. In order to reduce the convergence time of the computation these complex corner flow features were not resolved in the computation. Furthermore, the influences of fully developed turbulent boundary-layers on the side and the top walls of the test section were neglected. However, the width of the test section computed was reduced by $1.5 \mathrm{~mm}$, a displacement height suggested by Hartfield, ${ }^{23}$ to account for the boundary-layer displacement effects not resolved computationally.

The injected air was assumed to be at Mach 1.7. This injection was assumed to be developed from a large reservoir at a pressure of $252 \mathrm{KPa}$. The stagnation temperature of this reservoir was assumed to be the same as the freestream value. In a combustor model with swept injector, the shock-wave generated by the compression ramp is used to "process" the injected gas. The swept ramp also generates streamwise vorticity necessary for mixing enhancement. An axisymmetric injector nozzle, with $3.3 \mathrm{~mm}$ diameter, exits at the rear face of the swept ramp. The static pressure and temperature, adjusted to match mass flow rate, are computed to be $40.5 \mathrm{KPa}$ and $109.5^{\circ} \mathrm{K}$, respectively. Initially, the injected gas flow was assumed to be one dimensional. However, since the experimental data contains a substantial amount of flow expansion characteristics, an additional simulation was conducted to show the importance of modeling the expansion behavior to match the experimental data. The expansion characteristic in this simulation was modeled with a source flow model where the total expansion angle was assumed to be 10 degrees. The injection angles for both computations are assumed to be 9.5 degrees.

The computations were performed using three structured grid. Only half of the combustor was simulated to reduce computational requirements. The XYplane located at the center of the combustor model was assumed to be the plane of symmetry. A typical multiple-block structured grid system used to resolve the swept-injector of Hartfield et. al. ${ }^{25}$ is shown in Figure 17. There are three blocks of grid; the first two blocks of grid were used to model the primary flow passage over and behind the ramp and the third block of grid was used to model the flow passage around the side of the injector. The first grid block of was 45 by 45 by 45 in size and the second grid block was 43 by 27 by 33 in size. The third grid block, 45 by 45 by 45 in size, was used to model the flow region behind the ramp injector and in the main combustor region of the model. Typically, these computations used a total of 220,563 grid cells and $13 \mathrm{CMW}$ of memory. The grid cells along the bottom wall surface and around the injectors of the combustor were stretched using a hyperbolic tangent function to maintain a near-wall non-dimensional height $\left(\mathrm{y}^{+}\right)$ of 1.0. The interfaces between the blocks were numerically handled according to the flux conservative technique. ${ }^{20}$ The circular injector was modeled with 42 rectangular grid cells. Typical convergence history for the numerical solution is shown by Figure 18. Two orders of reduction in global residual is assumed to be adequate for obtaining a converged solution. This required approximately 10 Cray YMP CPU hours and about 2000 iterations.

The computations were conducted using air as the injected gas to match the mass and viscous characteristics of the experiment where the injectant mole fraction was measured using PLIIF. The inlet boundary-layer characteristics were developed from the log-law relationship and the thermal profile was generated using a parabolic relationship. ${ }^{26}$ An adiabatic wall boundary condition along with no-slip conditions were maintained only at the lower surface and the surface around the injector. Figure 19 shows the computed mass flow rate distribution inside of the combustor model. The ideal freestream and the injected mass flow rates are 0.090 $\mathrm{Kg} / \mathrm{s}$ and $1.49 \mathrm{~g} / \mathrm{s}$, respectively. The computed mass flow rate including the boundary-layer displacement effect is $0.0856 \mathrm{Kg} / \mathrm{s}$. The overall numerical error of this mass flow rate computation is about 2 percent.

A schematic of the flow field structure generated by the swept-ramp injector is shown in Figure 16. This ramp surface generates a shock-wave with a computed pressure ratio $\left(\mathrm{P}_{2} / \mathrm{P}_{1}\right)$ of 1.41 as compared to the ideal inviscid value of 1.65 . This shock-wave is then reflected back into the main flowfield further downstream behind the back-face of the ramp. The structure of this shockwave reflection is clearly illustrated by the centerline density contour shown in Figure 20. This shock-wave pattern is also remarkably similar to the schlieren photograph of the test section taken by Hartfield et. al. ${ }^{25}$ All of the key shock-wave characteristics, including interaction of the Mach disk and the reflected shock-wave at the triple point, have been reasonably captured. However, much higher grid resolution will be required to fully resolve the triple interaction region in quantative detail.

Comparisons of the centerline mass-fraction contour generated from the computed result and measured data are shown in Figure 21 and 22. These figures show good qualitative and quantitative agreement between the 
experimental measurements and the computed results. Figure 21 shows the mass fraction contour predicted by an injector model without the expansion characteristic. This comparison clearly shows that the injected stream of gas near the exit plane is much narrower than the experimentally measured contour. At the same time, the peak mass fraction occurs much further downstream than expected. This seems to suggest that the injection generated in absence of the initial expansion is far less efficient in promoting mixing. Figure 22 shows the centerline mass fraction contour generated from a numerical solution where the initial expansion was modeled as a source flow. This mass fraction contour is in much closer agreement with the measured data. The initial plume behavior and the extent of the peak mass fraction penetration down stream is better predicted.

Figures $23 \mathrm{a}$ and $23 \mathrm{~b}$ show comparisons of the computed mass-fraction contours with the contours generated by experimental measurements at several downstream locations. These figure show that the flowfield and the mixing characteristics generated by the swept ramp are well captured by the computation. The streamwise vorticity generated by the swept-ramp causes the injected fuel stream to be lifted from the floor and roll onto itself, developing a butterfly-like shape. This leads to rapid mixing of the injected air with the freestream air. The downstream distance to the location where the roll-up occurs and the peak mass fraction value computed are in agreement with the experimental data. Similar to the earlier transverse injector prediction, these figures also clearly show that the spreading rate of the injected gas is not captured by the numerical model. The spreading rate can also be characterized by the cross sectional area occupied by each mass fraction level. The mixing efficiency prediction using the earlier definition of 4 to 75 mass fraction limit is compared with the experimental data in Figure 24. Clearly, the predicted efficiency curves is lower than the efficiency curve generated using the measured data. This is a clear indication that the spreading rate predicted is much lower and occurs on a narrower region than the experimental observations.

\subsection{Streamwise Mach 3.0 Swept Injectors of Davis and Hingst}

Further complexities were introduced in the experimental study conducted by Davis and Hingst ${ }^{22}$. In that study, primary effects of the pressure ratio between the injected gas and the freestream gas on mixing characteristics were investigated over a range of operating conditions. A swept ramp with three rectangular injectors was used in their investigation. Figure 25 shows the typical geometry of the swept injector model. A matched pressure case was simulated to show that even very complex geometries with multiple injectors can be accurately predicted by the present numerical technique.
The freestream Mach number of the Davis and Hingst experiment was 3.0. The stagnation pressure and temperature were $206 \mathrm{KPa}$ and $294^{\circ} \mathrm{K}$, respectively. The injected ethylene-seeded air has a stagnation pressure of $206 \mathrm{KPa}$ and stagnation temperature of $294^{\circ} \mathrm{K}$. The static pressure for both the injected gas and the freestream was assumed to be $5.6 \mathrm{KPa}$. The injector exit conditions were assumed because independent measurements of quantities, such as the injector mass flow rate or pressures and temperatures, were not available for a more definitive characterization of the injector exit condition. A 10 degree compression ramp with a swept angle of 9.4 degrees was used to generate the combustor flowfield. The height $(\mathrm{H})$ of this compression ramp is $4.91 \mathrm{~cm}$. A typical schematic of this injector/combustor flowfield is shown in Figure 26. The computation resolved the fully developed turbulent boundary-layers on all three walls of the test section. The incoming boundary-layer was also modeled, using a profile generated from the log-law assumptions. Modeling of the incoming boundary-layer characteristics is important in this situation because the size and strength of the streamwise vorticity generated by the swept ramp are greatly affected by the ratio of the ramp height to boundary-layer thickness.

The centerplane of the $1 \mathrm{ft}$. by $1 \mathrm{ft}$. supersonic tunnel test section was assumed to be the plane of symmetry. Therefore, only one and a half of the three injectors were resolved in the computation. Figure 27 illustrates a typical four block grid system used to model the combustor flow field of Davis and Hingst. ${ }^{22}$ The first grid block of grid, 45 by 45 by 45 in size, was used to model the flow upstream of the ramp injector. The second and third blocks of grid, 19 by 25 by 45 and 21 by 21 by 45 in size, were used to model the flow region between the injectors. The fourth grid block, 65 by 45 by 45 in size, was used to model the flow region behind the ramp injector and in the main combustor region of the model. This grid system required $14 \mathrm{CMW}$ of memory. The grid cells along the three side walls were stretched using a hyperbolic tangent function to maintain a non-dimensional height $\left(\mathrm{y}^{+}\right)$of approximately 1.0. Typically, 144 rectangular cells were used to model an injector exit area. Figure 28 shows a typical convergence history of the numerical solution obtained. Approximately 2000 iterations and 16 Cray YMP CPU hours were needed to achieve a two orders of magnitude reduction in residuals required for convergence. Figure 29 shows the computed mass flow rate distribution inside of the combustor model. The mass flow rates computed from the numerical solution are $5.06 \mathrm{Kg} / \mathrm{s}$ for the freestream flow and $0.232 \mathrm{Kg} / \mathrm{s}$ for the injected gas flow as compared to the ideal freestream and the injected mass flow rates of $5.30 \mathrm{Kg} / \mathrm{s}$ and $0.237 \mathrm{Kg} / \mathrm{s}$, respectively. The small difference in the freestream mass flow rate is the result of the boundary-layer displacement effect not accounted for in the ideal approximation. 
Figure 30 shows the centerplane density contour and Figure 31 shows the centerplane Mach number contour. These two figures clearly illustrate the complex flow behavior inside of this combustor model. The Mach number contour shows that the turbulent boundary-layer on the top and bottom walls of the test section and the leading shock-wave, generated by the 10 degree ramp, has been resolved by the computation. The ramp generated shock-wave has a computed pressure ratio $\left(\mathrm{P}_{2} /\right.$ $\mathrm{P}_{1}$ ) of 1.82 ; as compare to the ideal inviscid pressure ratio is 2.07 . This ramp shock-wave interacts with the turbulent boundary-layer on the top wall of the test section at a location $54.5 \mathrm{~cm}$ from the leading edge of the ramp and is reflected down towards the injected stream of gas at the bottom of the tunnel. The final interaction of the shock-wave and the injected gas occurs near the end of the computational domain. The shock-wave/ boundary-layer interaction occurring at the top wall determines the shock-wave reflection characteristic. Therefore, adequate grid resolution was used to qualitatively resolve the separation region. However, quantitative characterization, such as skin friction or wall temperature, was not possible because of insufficient near-wall and near separation bubble grid resolution. The shock-wave/shear-layer interaction can also be an important physical mechanism which can be used to enhance mixing. However, for the problem considered, the reflected shock-wave is too weak to significantly change the flow behavior. This weakness is further complicated by the numerical diffusion which caused the shock-wave to diffuse in the coarse mesh regions located at the center of the computational domain further reducing the strength and the resolution of the reflected shock-wave.

Comparisons between the measured and computed mass fraction and Mach number contour are shown in Figures 32 thorough 34 . These contours were measured at $90.3 \mathrm{~cm}$ downstream of the ramp's leading edge. The (species) volume fraction measured using the trace gas technique $^{21}$ is equivalent to the computed mass fraction since both gases are air with the same molecular mass. Figure 32 and Figure 33 compare the mass fraction contours generated by the computation and the measured data. Computational results from using two different turbulent Schmidt numbers are shown in these figures. These comparisons show that the turbulent mass diffusion characteristic predicted using the Baldwin-Lomax turbulence model is inadequate. Figure 32 shows that if the turbulent Schmidt number is set to a value of 1.0, the turbulent diffusion contribution is much too small. As a result, the measured peak value of the mass fraction was over predicted by 23 percent. Figure 33 shows that this difficulty can be corrected by adjusting the turbulent Schmidt number to 0.50 to increase the effect of turbulence on the mass diffusion. This change in the model formulation captures the peak value of the mass fraction experimentally observed. However, it should be noted that, as with our earlier observation, the effect of wake is modeled empirically in the Baldwin-Lomax model formulation for wall bounded situations without much consideration for free shear flow situations. Therefore, closer scrutiny of the wake function is needed to determine the exact nature of the model deficiency in mixinglayers. These comparisons also show that the computed peak of the mass fraction is in a much more outward location than the experimentally observed peaks. Two cores of the mixing jets are also slightly further apart than in the experimental data. These differences are due to the lower swept angle used in the computational model to maintain non-zero and non-singular volume cells at the innermost point between the injectors.(see inset of Figure 25) The lower swept angle causes a change in the strength of the streamwise vorticity generated leading to a shift in the peak mass fraction location. However, the overall mass fraction peak as well as the major portion of the flow characteristics has been captured by the computation.

Figure 34 compares the computed and experimental Mach number contours. The computed result is in qualitative agreement with the experimental data. However, the average value of the Mach number predicted at the core of the mixing region is lower than the measured value. However, the computations were able capture the boundary-layer entrainment under the mixing region characterized by the low Mach number peaks shown in the figure. This entrainment is caused by the streamwise vorticity generated by the swept ramp and begins at the tail end of the mixing core region. Furthermore, it is important to note that more definitive characterization of the injector exit condition is required to improve the quantitative agreement with the experimental data.

\section{Concluding Remarks}

A numerical study was conducted to evaluate the performance of wall mounted fuel-injectors designed for potential Supersonic Combustion Ramjet(SCRAM-jet) engine applications. During this study, a capability of the RPLUS code to predict non-reacting flow fields inside combustor models with complex geometry has also been evaluated. Comprehensive comparisons of experimental and measured velocity, temperature, pressure, and mass fraction profiles show that many of the key flow features observed in the experiments are reasonably captured by the computations. These flowfield features include separation, streamwise vorticity generation, and shock-wave interaction effects. These comparisons also show that with several simple turbulence model modifications for multiple wall influences, complex features of the three dimensional combustor/injector flowfields can be reasonably predicted. However, these comparisons also reveal that the spreading rate, diffusion characteristics of the injected gas and the sepa- 
ration characteristics(i.e. wall temperature, bubble size) of the boundary-layer are not well predicted by a popular zero-equation Baldwin-Lomax turbulence model with a simple gradient-diffusion model for turbulent species diffusion. The diffusion characteristic of this turbulence model has been improved by using a calibrated value of the turbulent Schmidt number. However, it is important to note that the modeled wall-bounded wake characteristics in the Baldwin-Lomax turbulence model should be further revised so that more accurate predictions of the mixing-layers can be made. Furthermore, better assessment of boundary-layer separation and shock-wave to shear-layer interaction characteristics require higher order models of turbulence.

\section{Acknowledgments}

This work was supported by NASA Lewis Research Center under the contract NAS 3-25266 with Drs. D. R. Reddy and L. Povinelli as monitors. The author wishes to thank Dr. D. Eklund. of NASA Langley RC, Dr. B. Northam of NASA Langley RC, Dr. S. Hollo of Uni. of Virginia, Prof. J. McDaniel of Uni. of Virginia, and Dr. D. Davis of NASA Lewis RC for their helpful suggestions and also providing me with valuable experimental data. The author also would like to acknowledge the helpful comments and suggestions of J. Carlettan and B. Duncan. Some of the computations presented in the work were conducted using the Cray YMP resource provided by the NAS.

\section{References}

1.Yu S.T. Tsai Y. L. and Shuen J. S., “ Three Dimensional Calculation od Supersonic Reacting Flow using LU Scheme," AIAA Paper 89-8910.

2. Kumar A., Bushnell D. M., and Hussani M. Y., “ Mixing Augmentation Technique for Hypervelocity Scramjets," AIAA Paper 87-1882.

3. Brown G. L. and Roshko A., " On Density Effects and Large Structure in Turbulent Mixing Layer," J. Fluid Mechanics, V. 64, no. 4, 1974, pp775-816.

4. Papamoschou D. and Roshko A., " Observation of Supersonic Free Shear Layers," AIAA Paper 86-0162, Jan 1986.

5. Ragab S. A. and Wu J. L., "Instabilities in the Free Shear Layer Formed by Two Supersonic Streams," AIAA Paper 88-0038, Jan 1988.

6. Guirguis R. H., Grinstein F. F., Young T. R., Oran E. S., Kailasanath K. and Boris J. P., " Mixing Enhancement in Supersonic Shear Layer," AIAA Paper 87. 0373, Jan. 1987.

7. Guirguis R. H., " Mixing Enhancement in Supersonic Shear Layer: III. Effect of Convective Mach Number," AIAA Paper 88-0701, Jan. 1988.
8. Mennon S. and McCormack R., “ Numerical Studies of Supersonic Mixing near Three-Dimensional Flameholder using an Implicit Navier-Stokes Solver," Proceeding of 4th Int. Sym. on CFD, UC at Davis, Sept. 1991, pp 801-806.

9. Drummond P. J., " Mixing Enhancement of Reacting Parallel Fuel Jets in a Supersonic Flow Field," Proceeding of 4th Int. Sym. on CFD, UC at Davis, Sept. 1991, pp288-295.

10. Rao G. V. and Hieba A. A., "Use of Secondary Flows for Rapid Mixing in SCRAM-jet Combustors," AGRAD Conference Proceeding No. 479, Dec. 1990. 11. Povinelli L. A. and Ehlers R. C., " Swirling Base Injection for Supersonic Combustion Ramjets," AIAA J., Vol. 10 No. 9, Sept. 1972, pp1243-1244.

12. Gutmark E. , Shadow K. C. and Wilson K. J. "Noncircular Jet Dynamics in Supersonic Combustion," J. of Prop., Vol.5 No. 5, Sept 1989, pp529-533.

13. Drummond P. J., Carpenter M. H., Riggins D. W. and Adams, M. S., " Mixing Enhancement in a Supersonic Combustor," NASP Tech. Memorandum 110.

14. Marble F. E., Hendricks G. J., and Zukoski E. E., "Progress Towards Shock Enhancement of Supersonic Combustion Process," AIAA Paper 87-1880, Jun. 1987.

15. Shuen J. S. and Yoon S., "Numerical Study of Chemically Reacting Flows using LU-SSOR Scheme," AIAA J. Vol. 27, No. 12, pp1752-1760.

16. Gordon S. and McBride B. J., " Computer Program for the Calculation of Complex Equilibrium Composition, Rocket Performance, Incident and Reflected Shocks and Chapman-Jouguest Detonation," NASA SP273.

17. Kanury, M. Introduction to Combustion Phenomena, Gordon and Breach, c 1977.

18. Baldwin B. S. and Lomax H., " Thin Layer Approximation and Algebraic Model for Separated Turbulent Flows," AIAA Paper 78-257.

19 Arnal D. and Cousteix J., "Numerical Study of Corner Flows," Three Dimensional Turbulent Boundarylayers, ed. Fernholz and Krause, Springer-Verlag, c 1982.

20. Moon Y. J., "Numerical Study of Supersonic Combustors by Multi-Block Grids with Mismatched Interfaces," AIAA Paper 90-5204.

21. Givi P., Steinburg C. and Drummond P., " Effects of Compressibility and Heat Release in a High Speed Reacting Mixing-Layer," to be published in Combustion Science and Technology

22. Davis D. O. and Hingst W. R., " Progress Toward Synergistic Hypermixing Nozzles," AIAA Paper 912264. 
23. Norham B. G., Greenberg I. and Byington , "Evaluation of Parallel Injector Configurations for Supersonic Combustion," AIAA Paper 89-2525, July 1989.

24. McDaniel J., Fletcher D., Hartfield R. and Hollo, S. "Staged Transverse Injection into Mach 2 Flow Behind a Rearward-Facing Step: A 3-D Compressible Test Case for Hypersonic Combustor Code Validation," AIAA Paper 91-5071, Dec 1991.

25. Hartfield R. Hollo S. and McDaniel J. " Experimental Investigation of a Supersonic Swept Ramp Injector Using Laser-Induced Iodine Fluorescence, " AIAA Paper 90-1518, June 1990.

26. Holden M. S., Heavener, G. and Lee J., "ShockWave/Turbulent Boundary-layer Interactions in High Reynolds Number Hypersonic Flows," Calspan-UB Research Center Report No. 86681.

27. Eklund, D. R. Drummond J. P. and Hassan H. A.,

"Calculations of Supersonic Turbulent Reacting Coaxial Jets," AIAA J. Vol. 28, No. 9, pp 1633-1641.

FIGURE 1. Geometry of Transverse Injectors Model

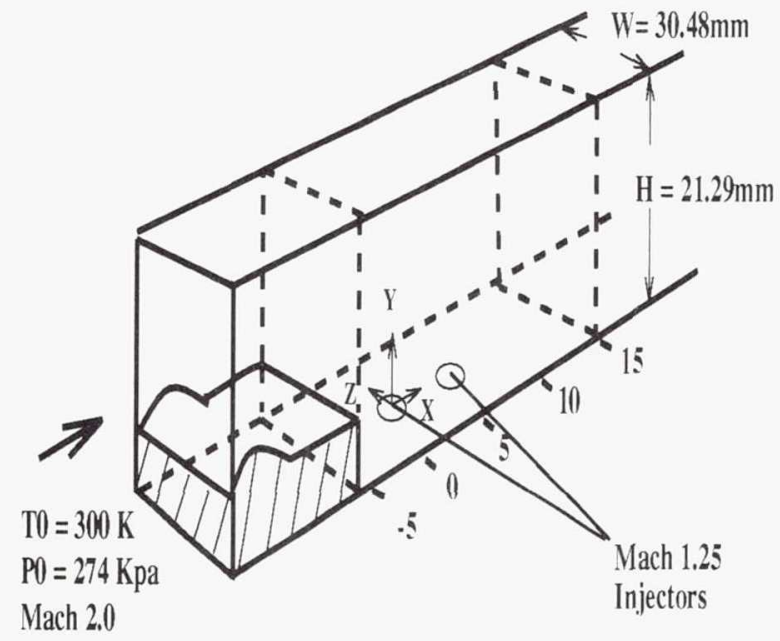

FIGURE 2. Schematic of the Combustor Flowfield

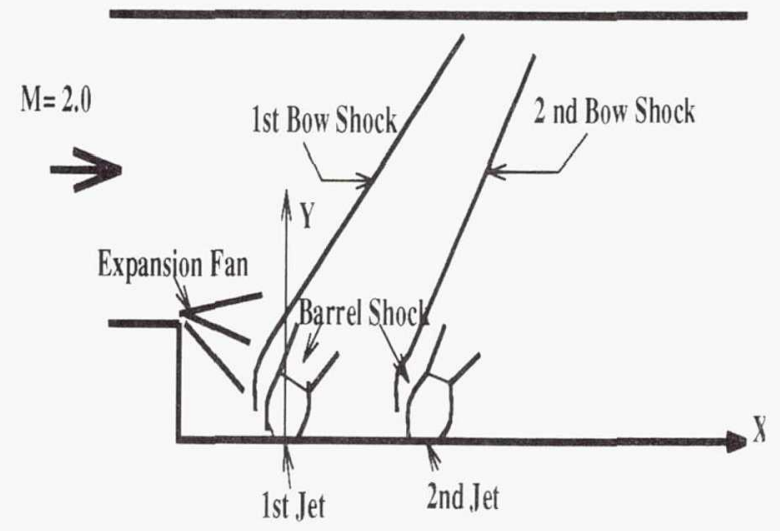

FIGURE 3. Typical Two Block Grid System

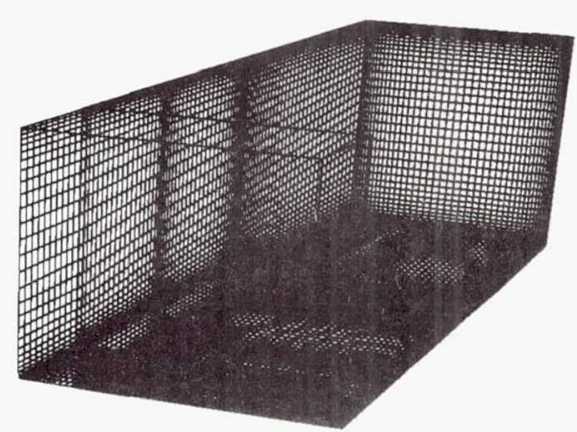

FIGURE 4. Typical Convergence History Convergence History/JANNAF

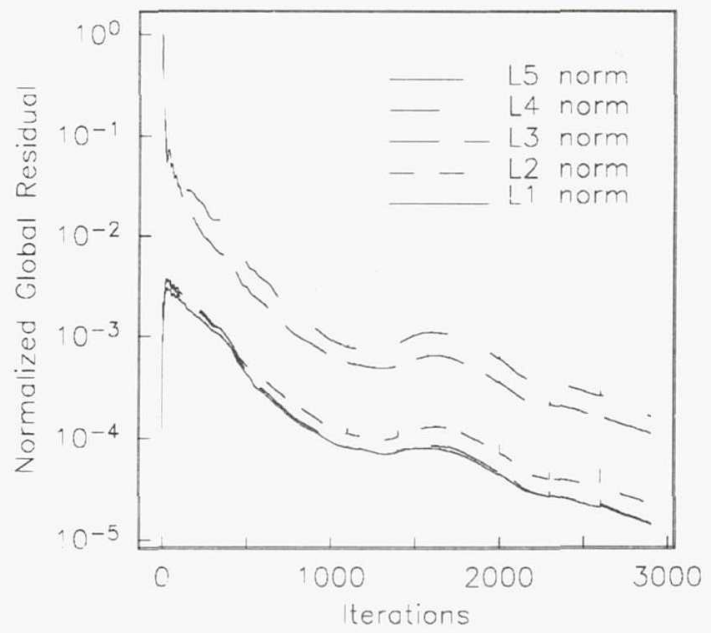

FIGURE 5. Computed Mass Flow Rates

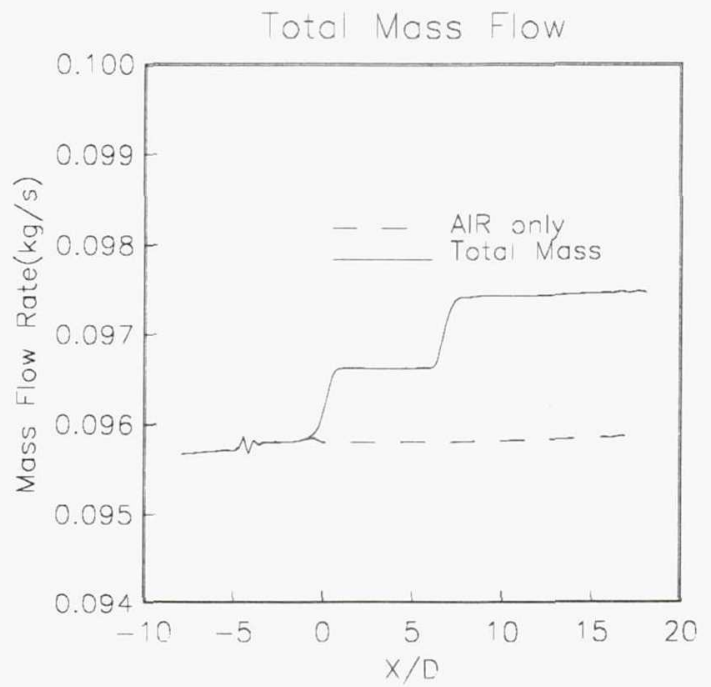


FIGURE 6. Profile at $X / D=0.0$ and $Z / D=0.0$ (a) V-velocity, (b) U-velocity, (c) Temperature, (d) Pressure
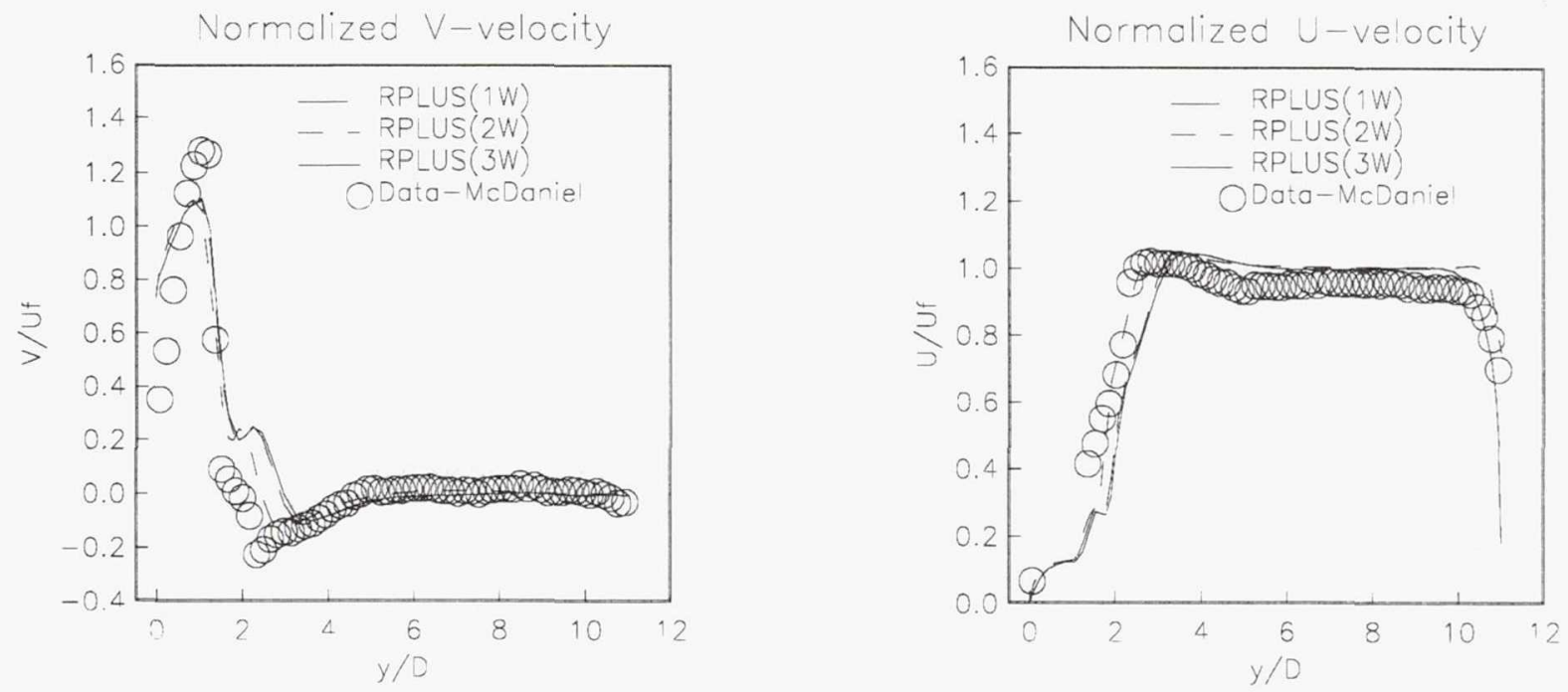

Normalized Temperature
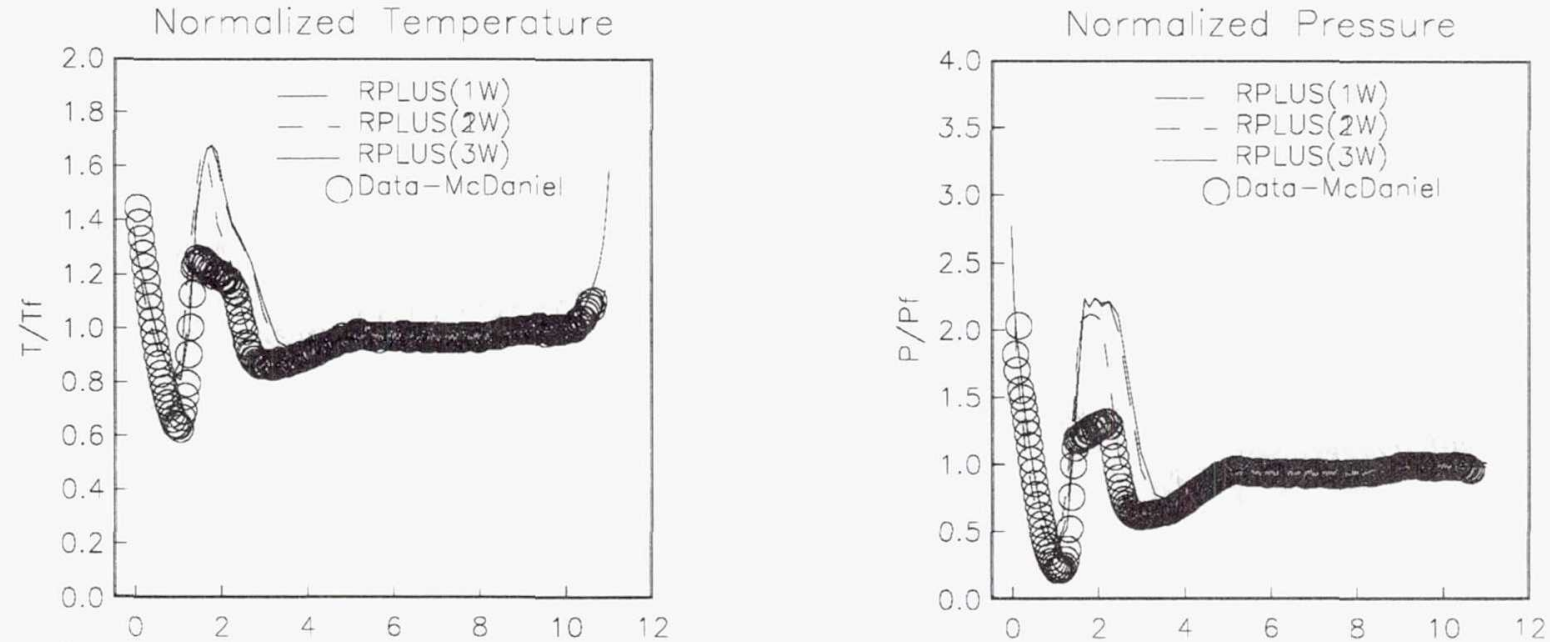

FIGURE 7. Profile at $X / D=3.1$ and $Z / D=0.0$ (a) V-velocity, (b) U-velocity, (c) Temperature, (d) Pressure
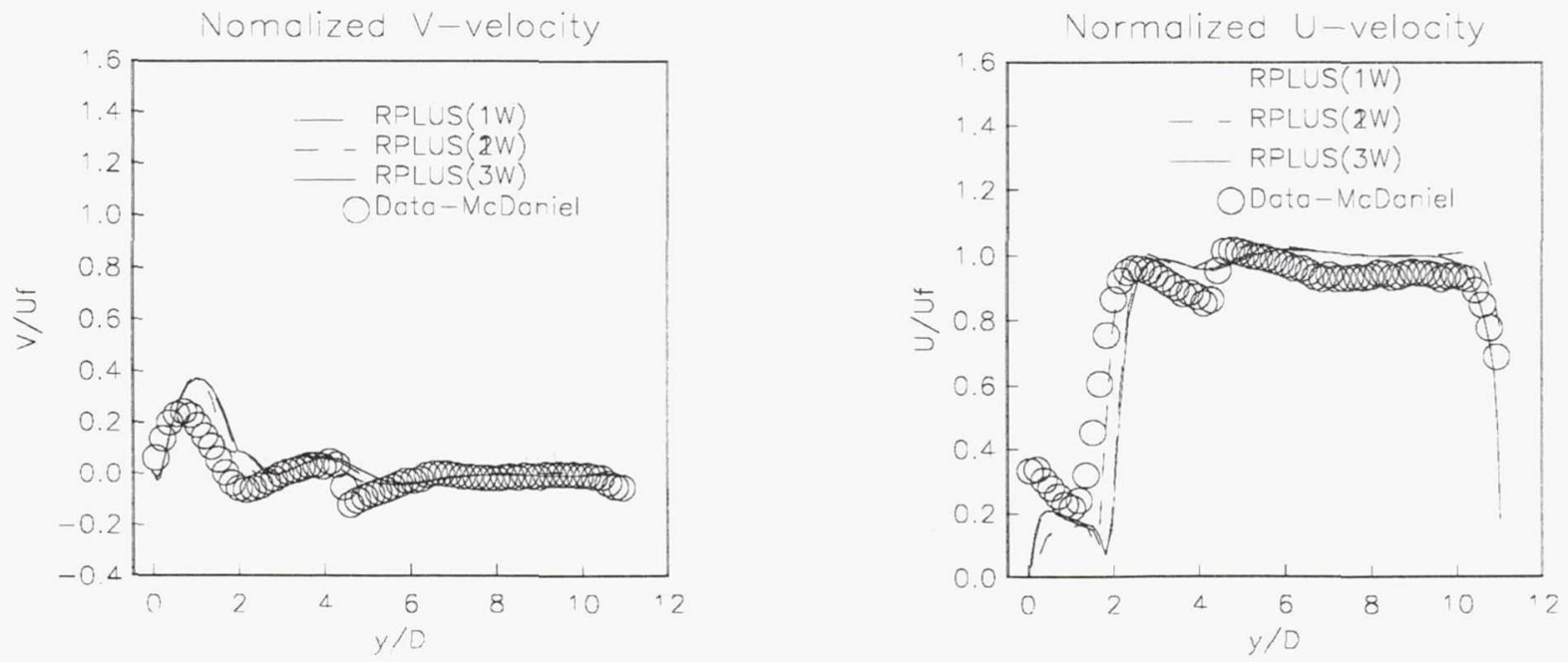
FIGURE 7 cont'd Profile at $X / D=3.1$ and $Z / D=0.0$
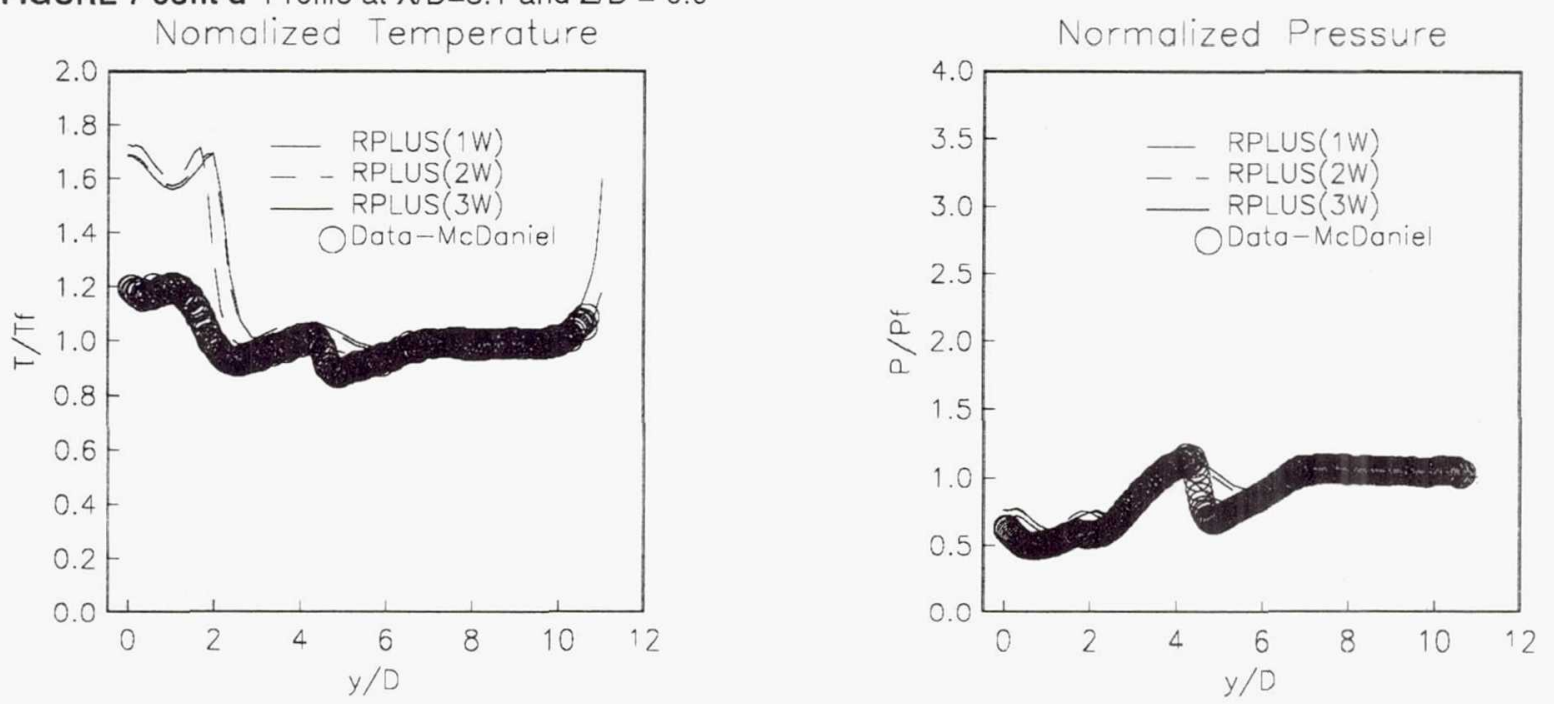

FIGURE 8. Profile at $X / D=6.6$ and $Z / D=0.0$ (a) V-velocity, (b) U-velocity, (c) Temperature, (d) Pressure
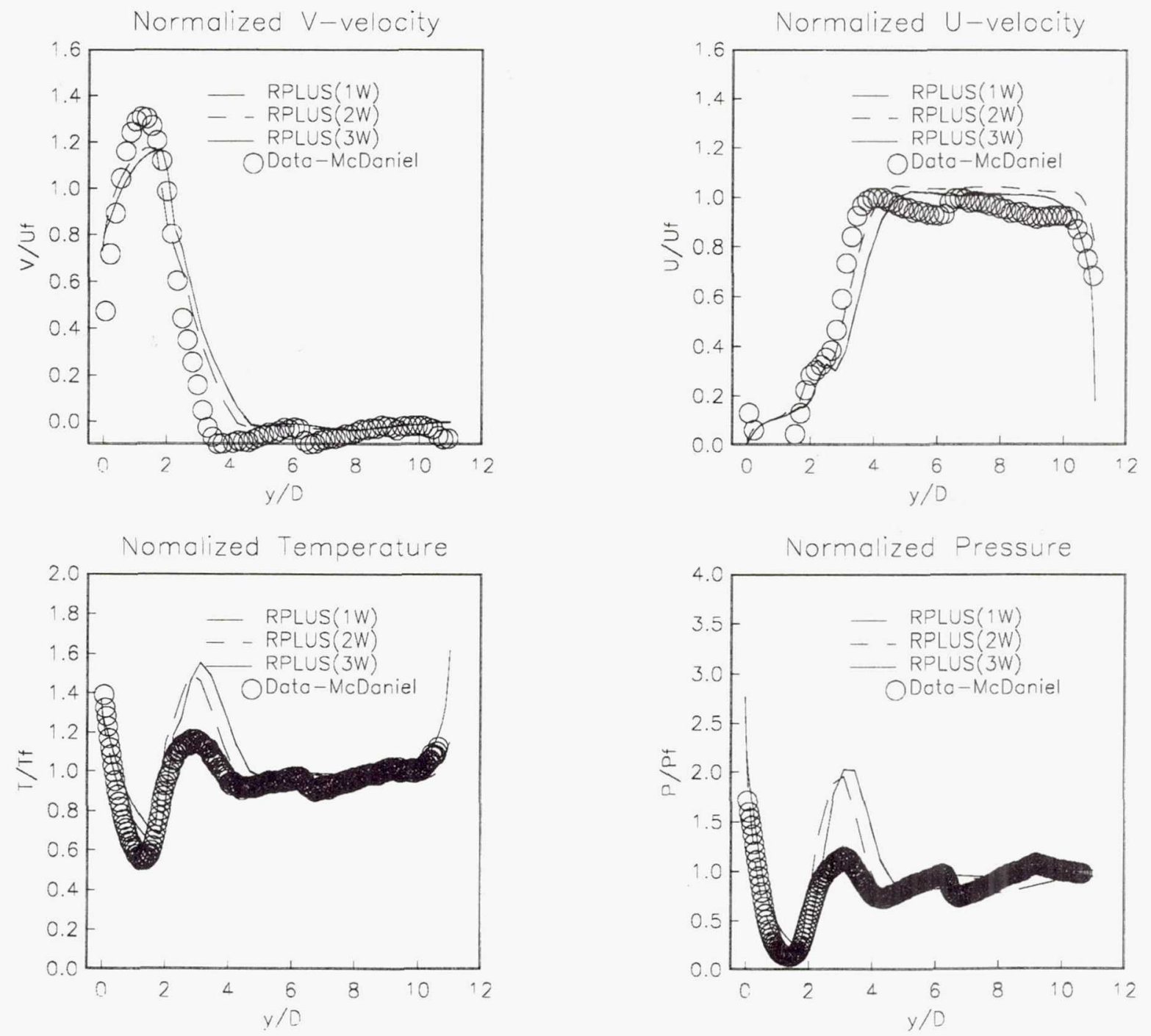
FIGURE 9a. Velocity Profile at $X / D=3.1, Z / D=0.50$

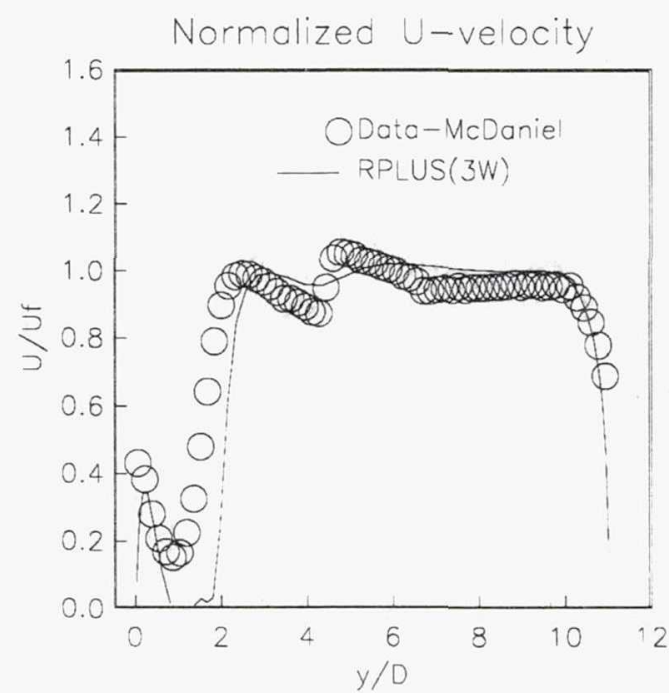

FIGURE 9b. Velocity Profile at $X / D=3.1, Z / D=0.50$

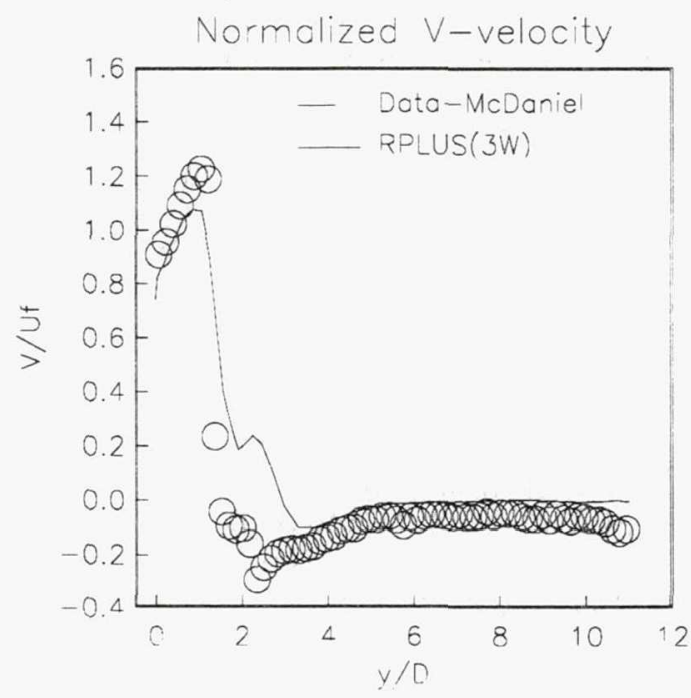

FIGURE 9c. Pressure Profile at $X / D=3.1, Z / D=0.50$

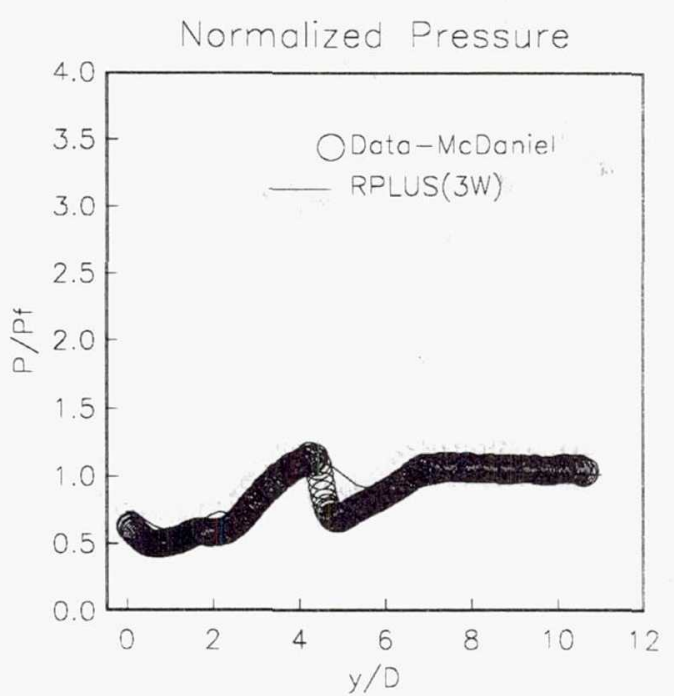

FIGURE 9d. Temperature Profile at $X / D=3.1, Z / D=0.50$

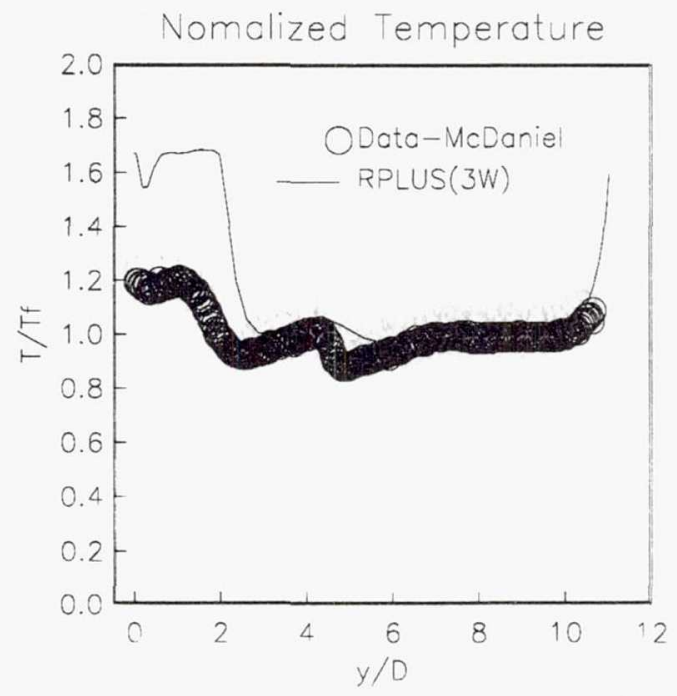




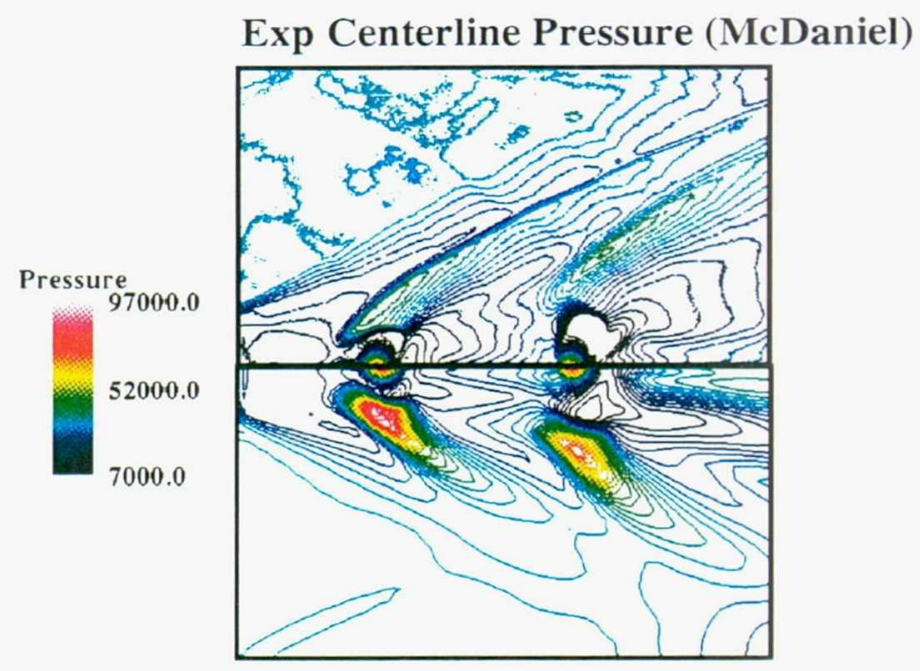

RPLUS Centerline Pressure

FIGURE 11. Centerline Temperature(in deg $\mathrm{K}$ ) Comparison( $\mathrm{Z} / \mathrm{D}=0.0$,

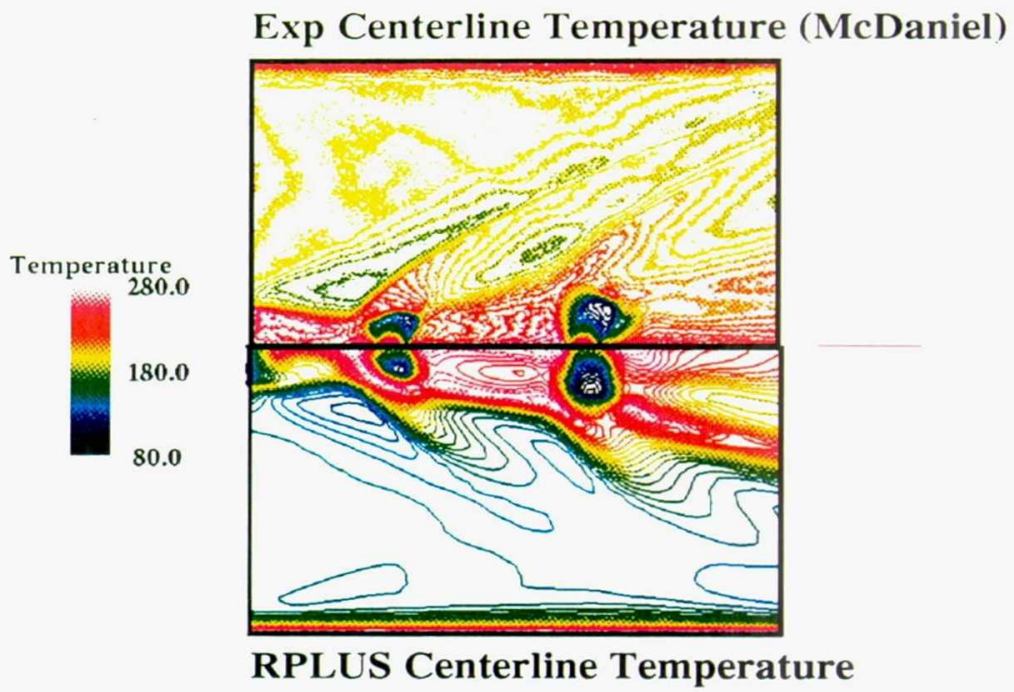


Page intentionally left blank 
FIGURE 12. Centerline Mass Fraction Comparison

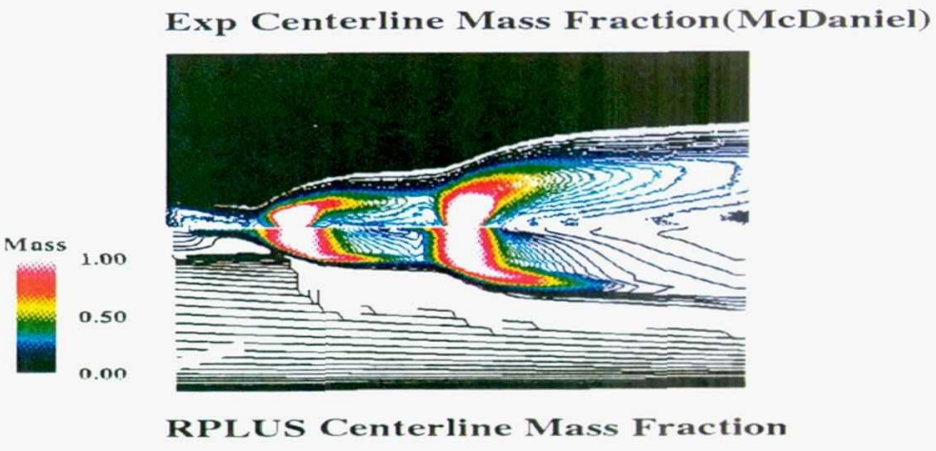

FIGURE 13. Cross Sections of Mass Fraction, (a)X/D=-3.0,(b)X/D=0.0,(c)X/D=3.1, (d)X/D=6.6
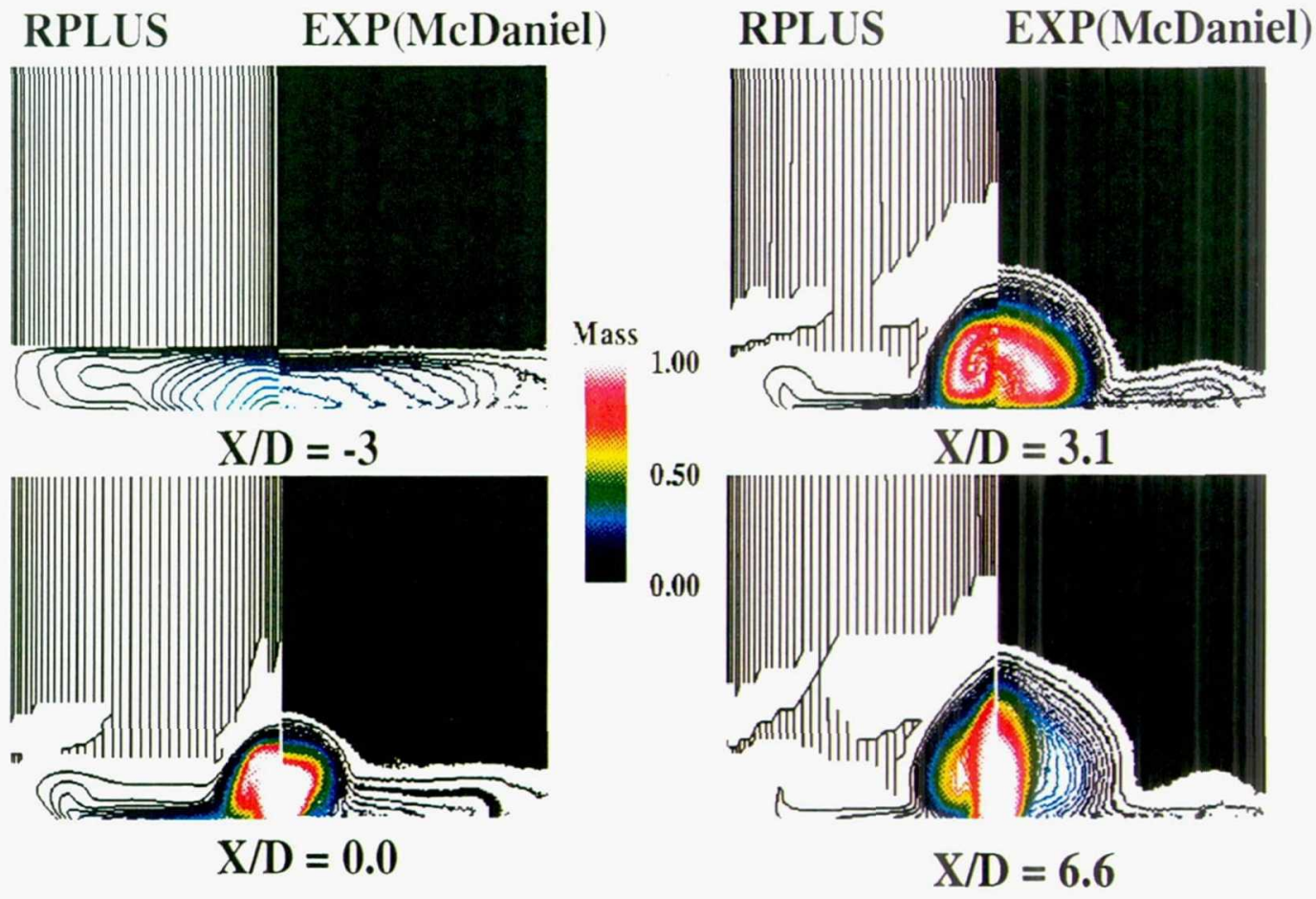
Page intentionally left blank 
FIGURE 14. One-Dimensional Mixing Schedule

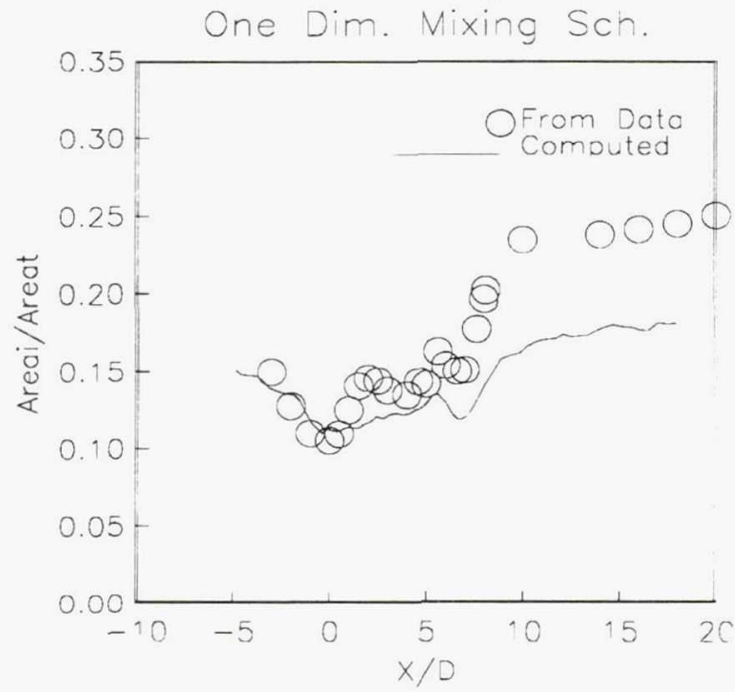

FIGURE 15. Swept-Injector Geometry of Hartfield

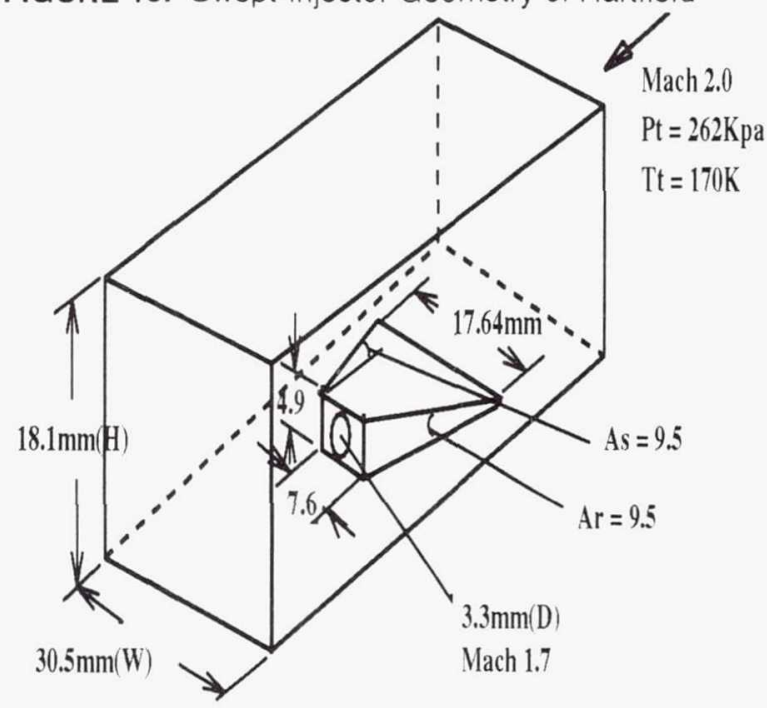

FIGURE 16. Schematic of Mach 2 Flowfield

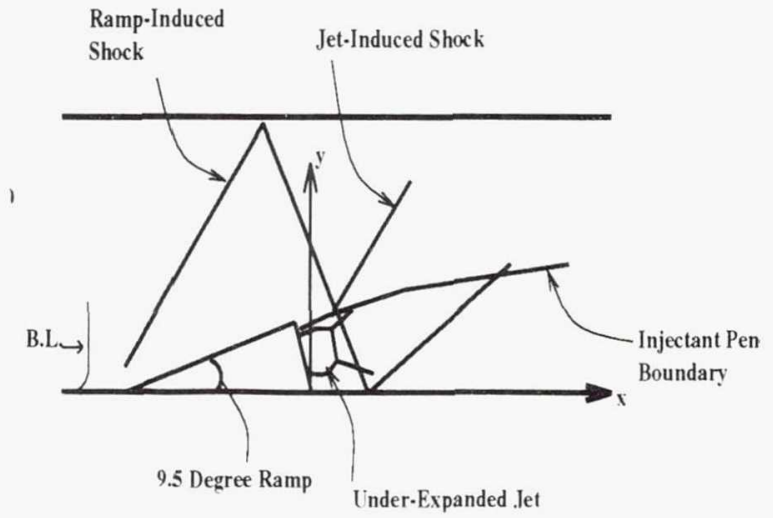

FIGURE 17. Three-Block Grid System Hartfield Model

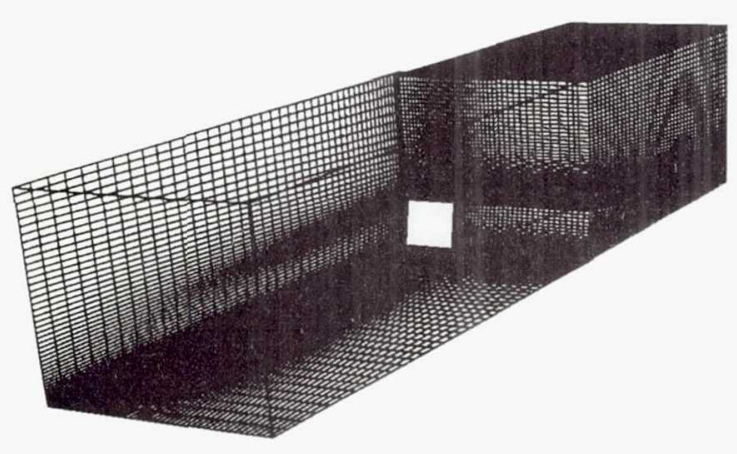

FIGURE 18. Convergence History of Mach 2.0 Flow

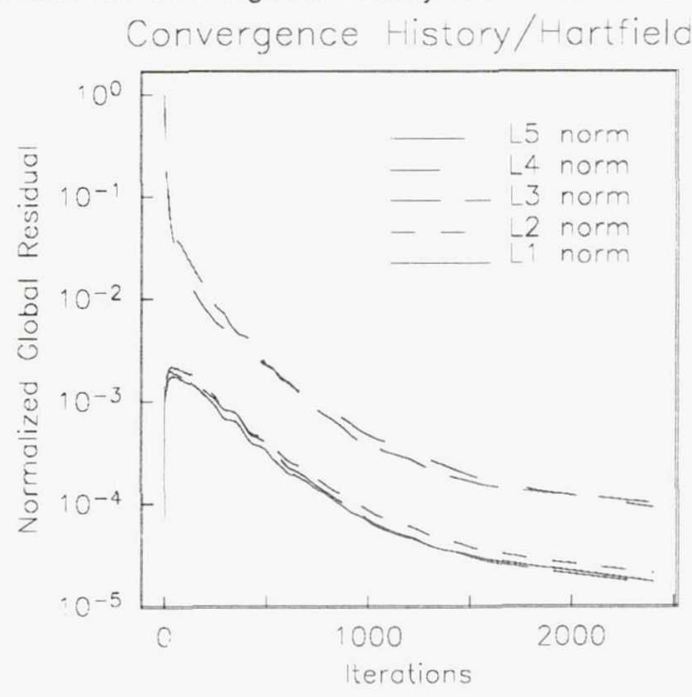

FIGURE 19. Total Mass Flow Rate

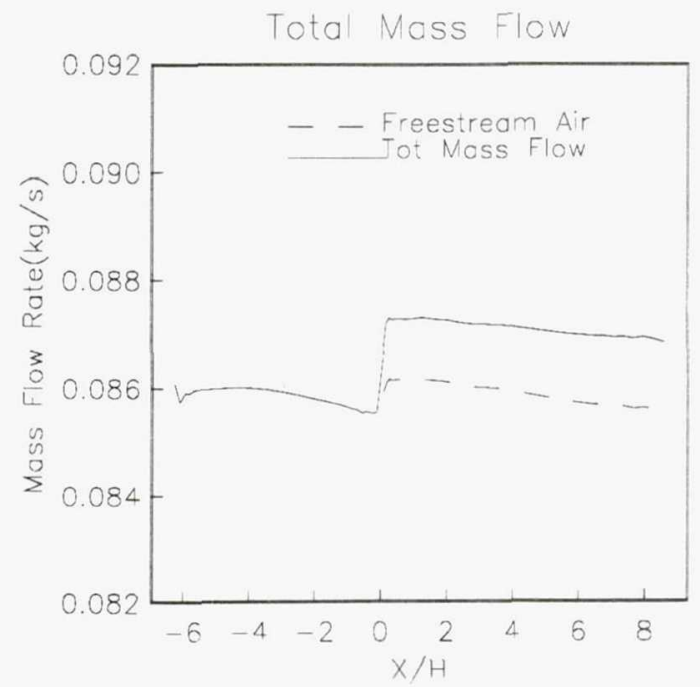


Page intentionally left blank 

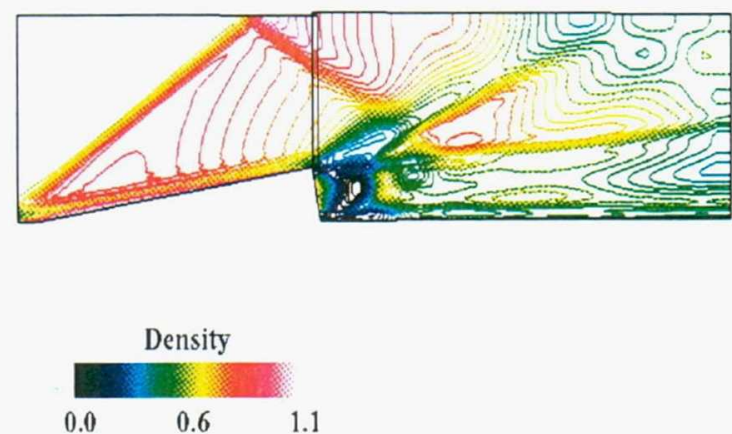

FIGURE 21. Centerline Mass Fraction Comparison

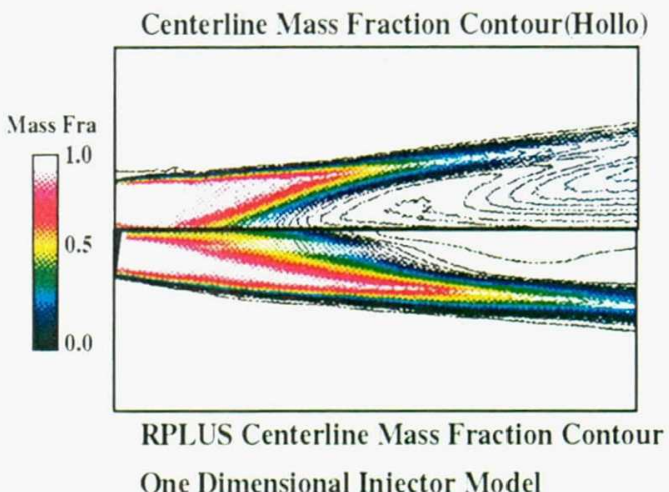

FIGURE 22. Centerline Mass Fraction Comparison

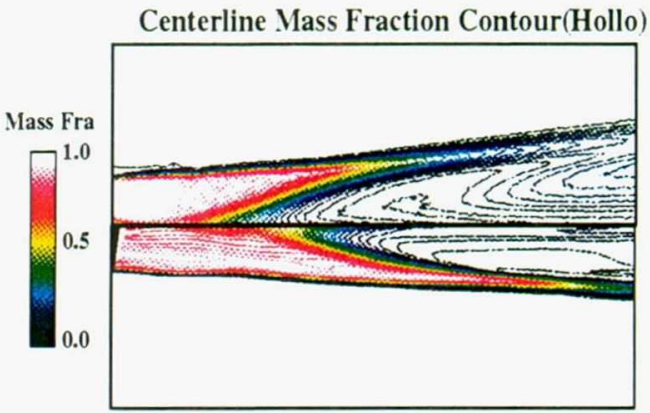

RPLUS Centerline Mass Fraction Contour 10 Deg. Source Flow Model

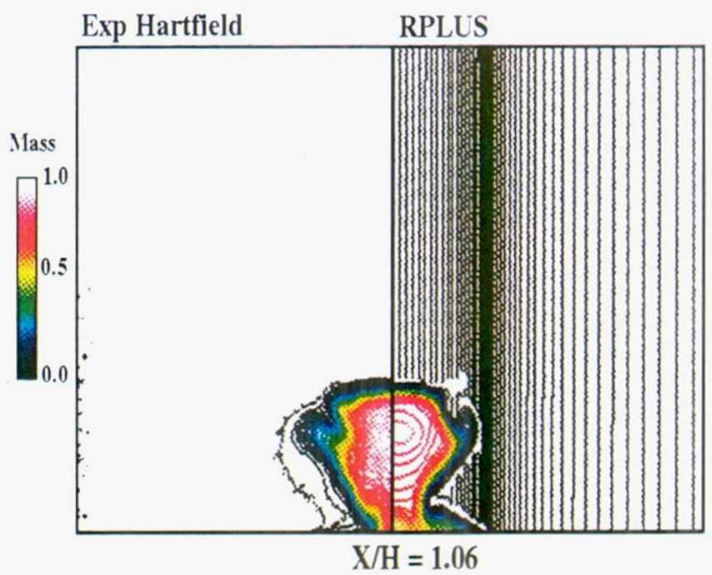

FIGURE 23 b. Cross Section Mass Fraction Comparison

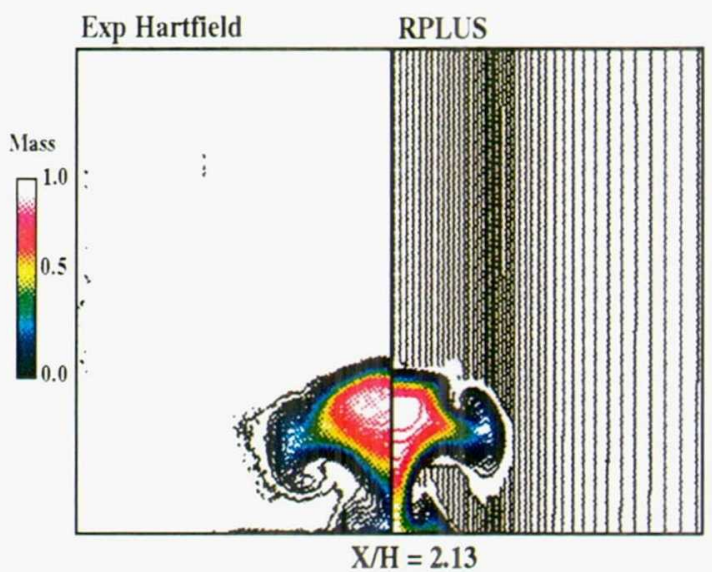

FIGURE 23 c. Cross Section Mass Fraction Comparison

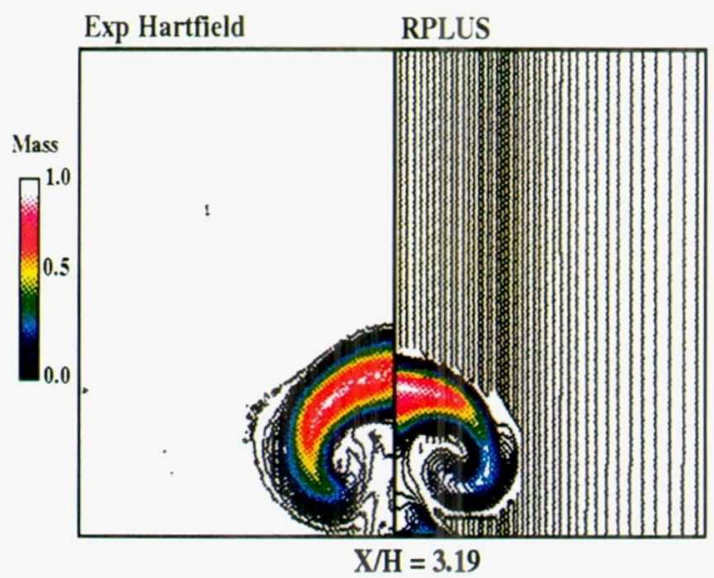


Page intentionally left blank 
FIGURE 24. Mixing Efficiency

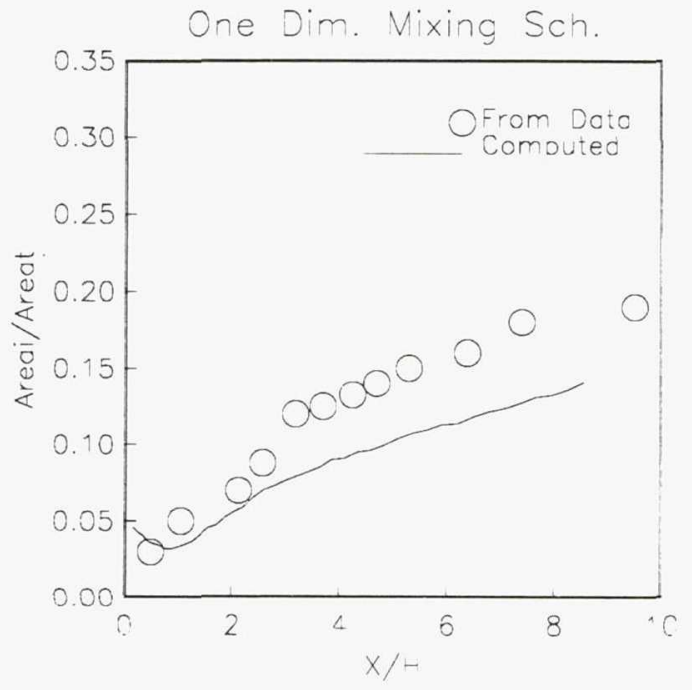

FIGURE 25. Swept-Injector Geometry of Davis

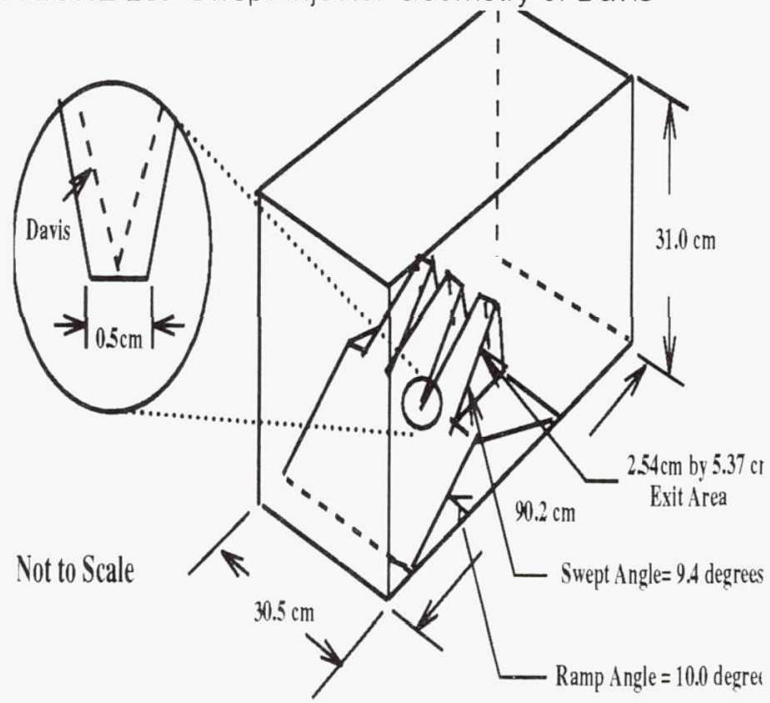

FIGURE 26. Schematics of Mach 3.0 Flowfield

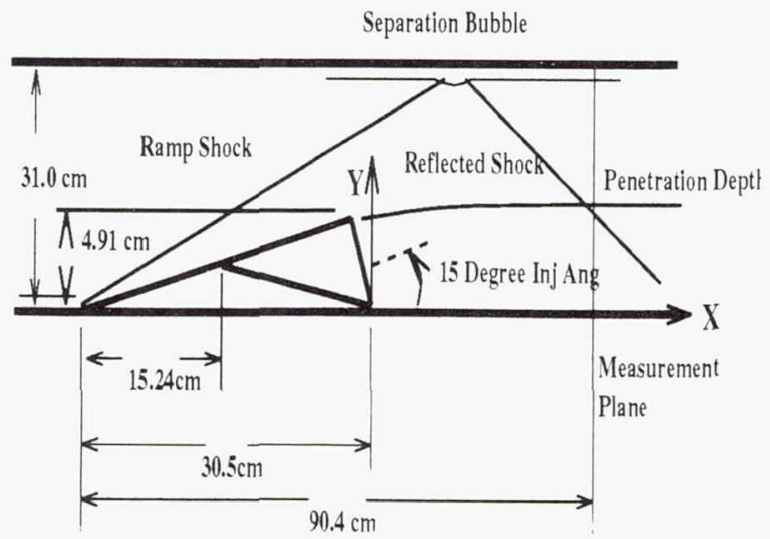

FIGURE 27. Four-Block Grid System of Davis' Model

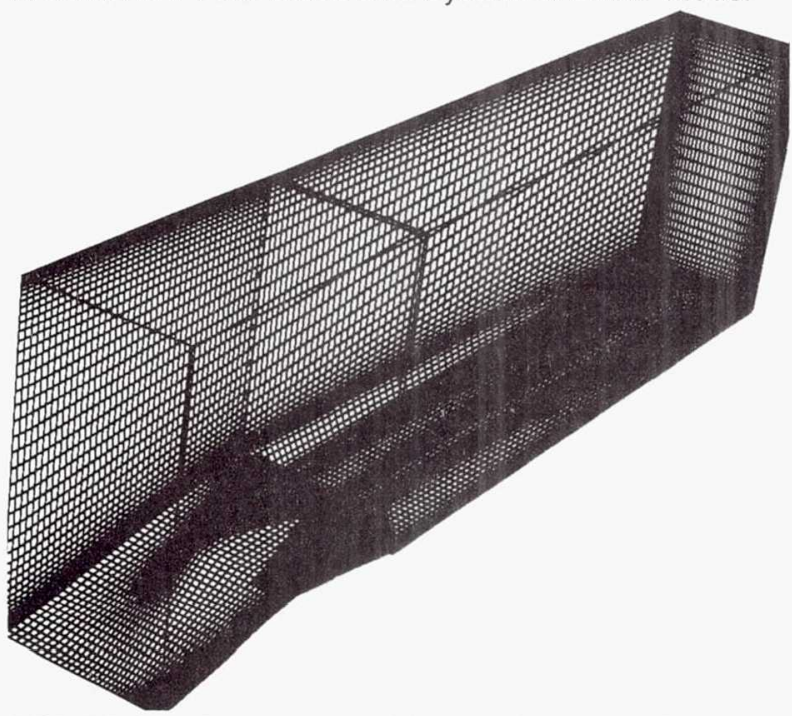

FIGURE 28. Convergence History For Mach 3 Flow

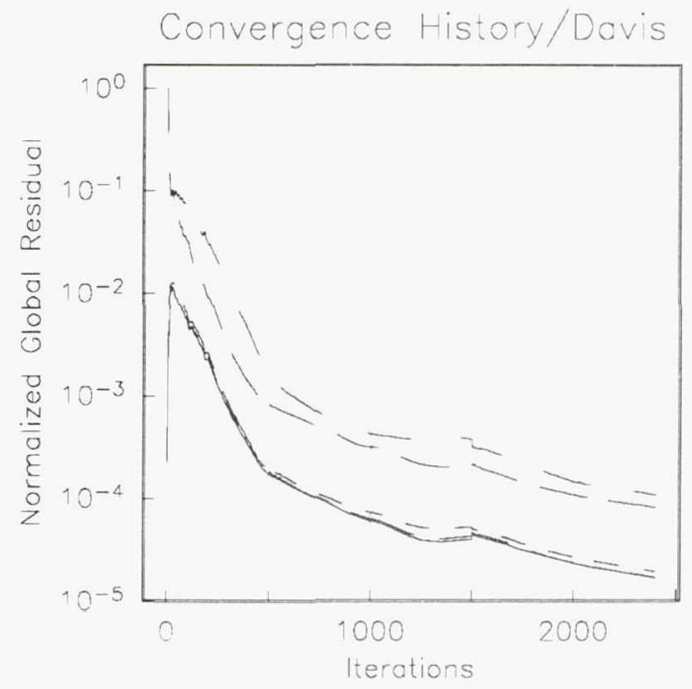

FIGURE 29. Total Mass Flow Rate

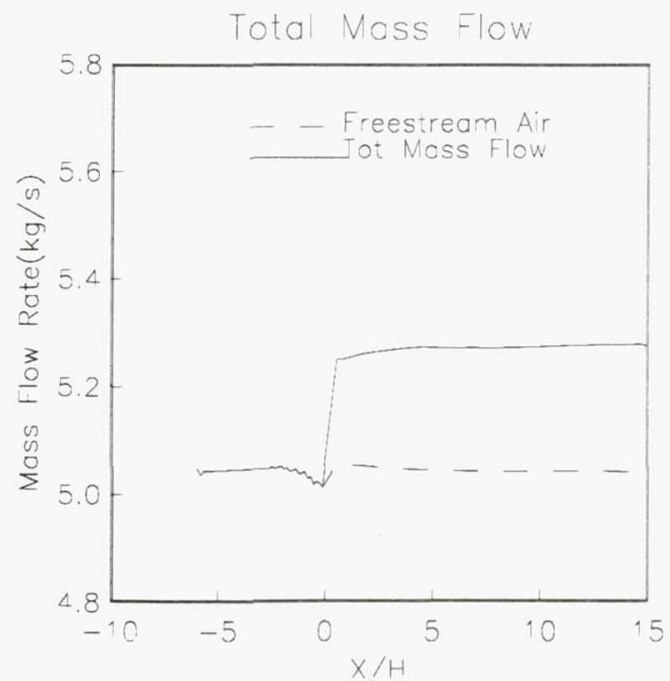


Page intentionally left blank 

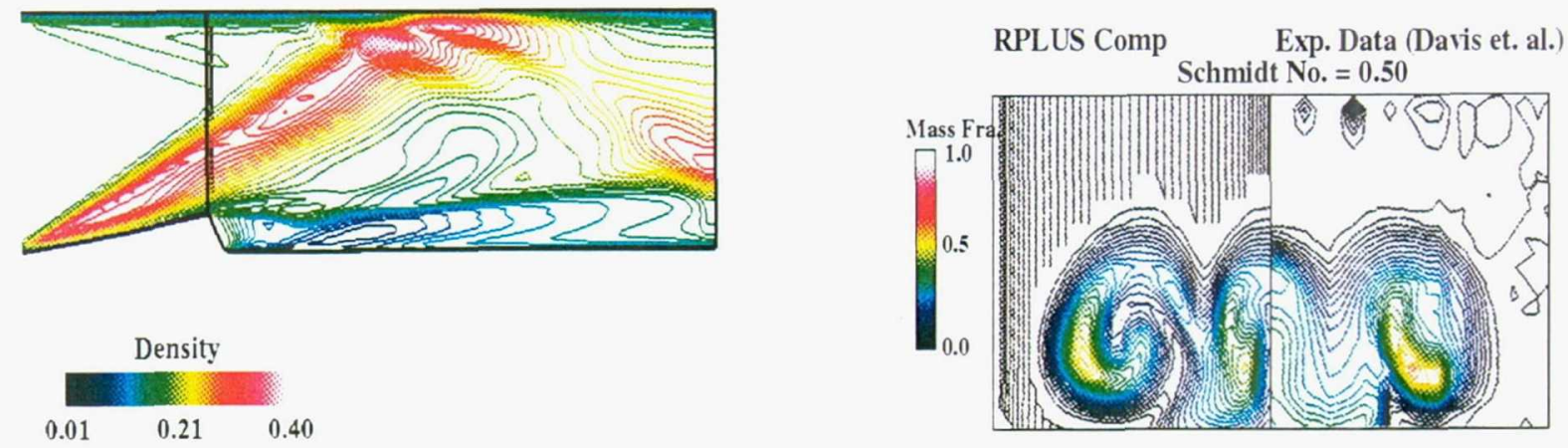

FIGURE 31. Centerline Mach Number Contour

FIGURE 34. Cross-Section Mach Number Comparison
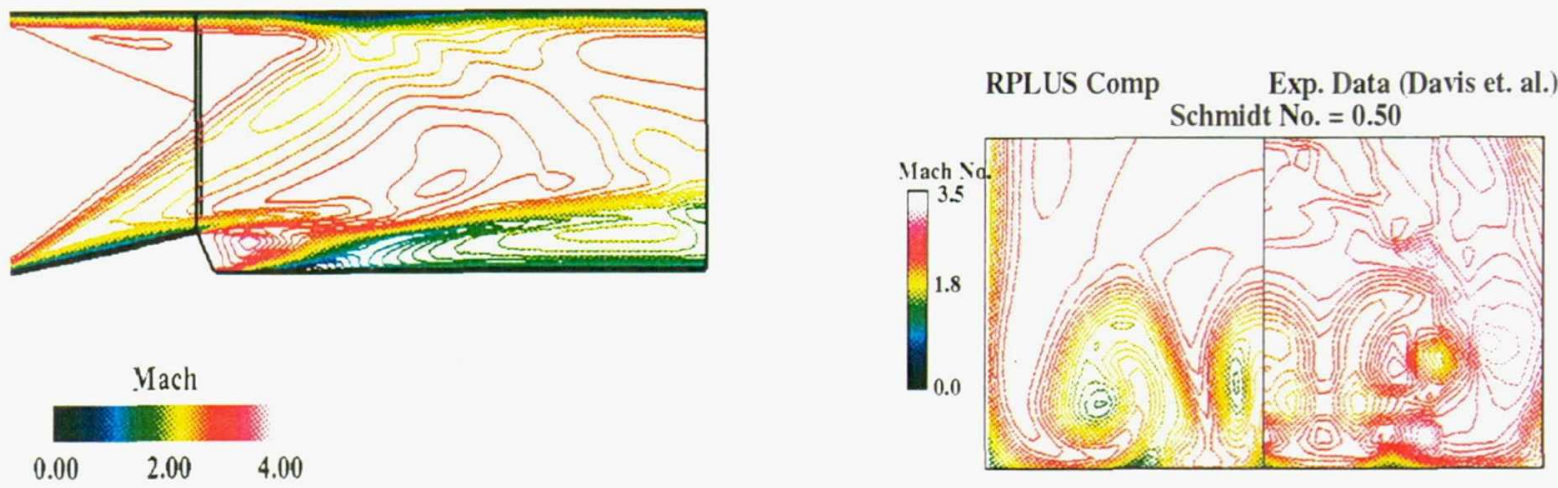

FIGURE 32. Mass-Fraction Cross Section Comparison

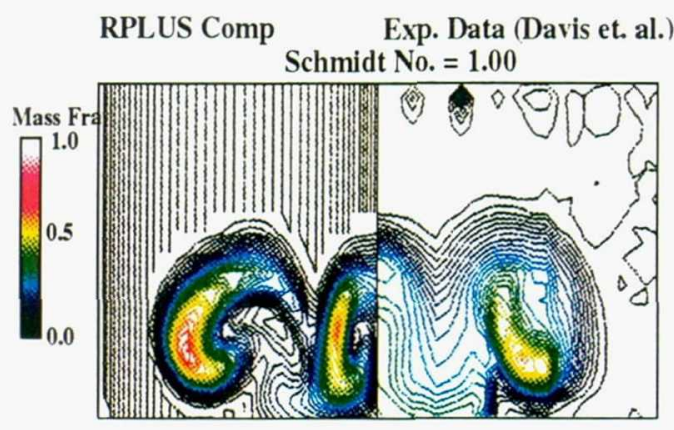


Public reporting burden for this collection of information is estimated to average 1 hour per response, including the time for reviewing instructions, searching existing data sources, gathering and maintaining the data needed, and completing and reviewing the collection of information. Send comments regarding this burden estimate or any other aspect of this Davis Highway, Suite 1204, Arlington, VA 22202-4302, and to the Office of Management and Budget, Paperwork Reduction Project (0704-0188), Washington, DC 20503.

\begin{tabular}{|l|c|c|}
\hline 1. AGENCY USE ONLY (Leave blank) & $\begin{array}{c}\text { 2. REPORT DATE } \\
\text { December } 1992\end{array}$ & $\begin{array}{r}\text { 3. REPORT TYPE AND DATES COVERED } \\
\text { Final Contractor Report }\end{array}$ \\
\hline
\end{tabular}

\section{TITLE AND SUBTITLE} 5. FUNDING NUMBERS

A Numerical Study of Mixing in Supersonic Combustors With Hypermixing Injectors

\section{AUTHOR(S)}

WU-505-62-40

J. Lee

\section{PERFORMING ORGANIZATION NAME(S) AND ADDRESS(ES)}

Sverdrup Technology, Inc. Lewis Research Center Group

2001 Aerospace Parkway Brook Park, Ohio 44142
8. PERFORMING ORGANIZATION REPORT NUMBER

E-7504

\section{SPONSORING/MONITORING AGENCY NAMES(S) AND ADDRESS(ES)}

National Aeronautics and Space Administration

Lewis Research Center

Cleveland, Ohio 44135-3191

10. SPONSORING/MONITORING AGENCY REPORT NUMBER

NASA CR-191027

AIAA-93-0215

\section{SUPPLEMENTARY NOTES}

Project Manager, D.R. Reddy

12a. DISTRIBUTION/AVAILABILITY STATEMENT 12b. DISTRIBUTION CODE

Unclassified - Unlimited

Subject Category 02

\section{ABSTRACT (Maximum 200 words)}

A numerical study was conducted to evaluate the performance of wall mounted fuel-injectors designed for potential Supersonic Combustion Ramjet (SCRAM-jet) engine applications. The focus of this investigation was to numerically simulate existing combustor designs for the purpose of validating the numerical technique and the physical models developed. Three different injector designs of varying complexity were studied to fully understand the computational implications involved in accurate predictions. A dual transverse injection system and two streamwise injector designs were studied. The streamwise injectors were designed with swept ramps to enhance fuel-air mixing and combustion characteristics at supersonic speeds without the large flow blockage and drag contribution of the transverse injection system. For this study, the Mass-Averaged Navier-Stokes equations and the chemical species continuity equations were solved. The computations wee performed using a finite-volume implicit numerical technique and multiple block structured grid system. The interfaces of the multiple block structured grid systems were numerically resolved using the flux-conservative technique. Detailed comparisons between the computations and existing experimental data are presented. These comparisons show that numerical predictions are in agreement with the experimental data. These comparisons also show that a number of turbulence model improvements are needed for accurate combustor flowfield predictions.

\section{SUBJECT TERMS}

Mixing injection; Hypermixing; Combuster; Scramjet, CFD

17. SECURITY CLASSIFICATION OF REPORT Unclassified

\section{SECURITY CLASSIFICATION OF THIS PAGE}

Unclassified
19. SECURITY CLASSIFICATION OF ABSTRACT Unclassified 
National Aeronautics and

Space Administration

Lewis Research Center

Cleveland, Ohio 44135

Official Business

Penalty for Private Use $\$ \mathbf{\$ 3 0 0}$

FOURTH CLASS MAIL

ADDRESS CORRECTION REQUESTED

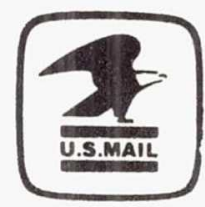

Postage and Fees Paid National Aeronaulics and Space Administration

NASA 451 